Compositional differences among Bright Spots on the Ceres surface

E. Palomba, A. Longobardo, M.C. De Sanctis, N.T. Stein ,

B. Ehlmann, A. Galiano, A. Raponi , M. Ciarniello,

E. Ammannito, E. Cloutis , F.G. Carrozzo, M.T. Capria ,

K. Stephan, F. Zambon, F. Tosi, C.A. Raymond, C.T. Russell

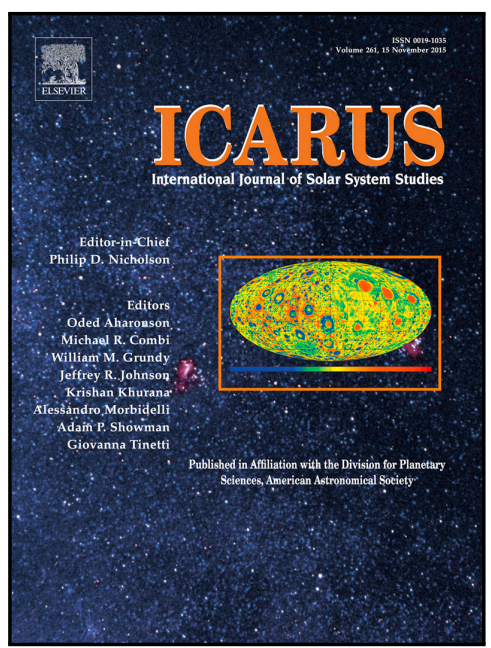

PII:

S0019-1035(17)30313-5

DOI:

10.1016/j.icarus.2017.09.020

Reference:

YICAR 12616

To appear in:

Icarus

Received date:

26 April 2017

Revised date:

8 September 2017

Accepted date:

18 September 2017

Please cite this article as: E. Palomba , A. Longobardo , M.C. De Sanctis, N.T. Stein , B. Ehlmann , A. Galiano, A. Raponi , M. Ciarniello, E. Ammannito, E. Cloutis , F.G. Carrozzo, M.T. Capria, K. Stephan, F. Zambon, F. Tosi , C.A. Raymond, C.T. Russell , Compositional differences among Bright Spots on the Ceres surface, Icarus (2017), doi: 10.1016/j.icarus.2017.09.020

This is a PDF file of an unedited manuscript that has been accepted for publication. As a service to our customers we are providing this early version of the manuscript. The manuscript will undergo copyediting, typesetting, and review of the resulting proof before it is published in its final form. Please note that during the production process errors may be discovered which could affect the content, and all legal disclaimers that apply to the journal pertain. 


\section{Highlights}

- A catalogue of bright spots on Ceres is presented

- Scatterplot analysis of $2.7,3.1,3.4,4 \mu \mathrm{m}$ band depth for each bright spot is presented

- Compositional difference between bright spots is discussed

- Some Peculiar Bright spots are discussed in detail

- A path for formation and evolution of Bright Spots on Ceres is proposed 


\title{
Compositional differences among Bright Spots on the Ceres surface
}

\author{
E. Palomba ${ }^{1}$, A. Longobardo ${ }^{1}$, M.C. De Sanctis ${ }^{1}$, N. T. Stein ${ }^{2}$, B. Ehlmann ${ }^{2,3}$, A. Galiano ${ }^{1}$, A. \\ Raponi $^{1}$, M. Ciarniello ${ }^{1}$, E. Ammannito ${ }^{1,8}$, E. Cloutis ${ }^{4}$, F. G. Carrozzo ${ }^{1}$, M. T. Capria ${ }^{1,5}$, K. \\ Stephan $^{6}$, F. Zambon ${ }^{1}$, F. Tosi ${ }^{1}$, C. A. Raymond ${ }^{7}$, C.T. Russell ${ }^{8}$ \\ ${ }^{1}$ INAF-IAPS, Rome, Italy (ernesto.palomba@iaps.inaf.it). ${ }^{2}$ Div. Geological and Planetary Sciences, Caltech, 1200 East California Boulevard, \\ Pasadena, California 91125, USA; ${ }^{3}$ Jet Propulsion Laboratory, Caltech, Pasadena, California 91109, USA; ${ }^{4}$ Dep. of Geography, University of \\ Winnipeg, 515 Portage Avenue, Winnipeg, Manitoba, Canada; ${ }^{5}$ ASDC-ASI, Via del Politecnico, 00133 Rome, Italy; ${ }^{6}$ DLR, Berlin, Germany; ${ }^{7} \mathrm{JPL}$, \\ California Inst. Tech, Pasadena, CA, USA; ${ }^{8}$ UCLA, Los Angeles, CA, USA.
}

\section{Abstract}

At the beginning of the Ceres investigation, the Dawn-NASA mission discovered a large bright spot (BS) in the Occator crater floor. Several other smaller bright spots were discovered during the following phases of the mission. In this paper, a complete survey for the detection of BS on the Ceres surface have been made by using the hyperspectral data acquired by Visible and Infrared Mapping Spectrometer (VIR). The hyperspectral images span the spectral range from 0.2 to $5 \mu \mathrm{m}$, by using two channel, the VIS channel with a spectral sampling of $1.8 \mathrm{~nm}$ and a IR channel with a spectral sampling of $9.8 \mathrm{~nm}$. Finally a catalogue of $92 \mathrm{BS}$ has been compiled and their compositional properties have been examined. In particular, five spectral parameters have been applied to perform the analysis: the photometrically corrected reflectance and four band depths, related to spectral absorptions at $2.7 \mu \mathrm{m}(\mathrm{OH}$ fundamental indicative of phyllosilicates), at $3.05 \mu \mathrm{m}$ (due to ammoniated clays), at 3.4 and $4.0 \mu \mathrm{m}$ (carbonate overtones). The $90 \%$ of BS are impactrelated features (ejecta, crater rim, crater floor, crater wall). The two brightest BS, Cerealia and Vinalia Faculae, are located on the Occator crater floor. Most of BSs show features similar to the average Ceres surface, which has low reflectance and is composed of Mg-phyllosilicates and ammoniated clays, with a reduced abundance of $\mathrm{Mg}$-Ca carbonates. Cerealia and Vinalia Faculae are a peculiar BS family, with a high abundance of Na-carbonates and Al-rich phyllosilicates. Oxo and a companion bright spot represents a third category, depleted in phyllosilicates and with a high to moderate albedo. Carbonate composition ranges from $\mathrm{Mg} / \mathrm{Ca}$ to $\mathrm{Na}$ components. Haulani, 
Ernutet, Kupalo, and other two BS's represent another group, with intermediate properties between the typical BS and the Oxo family: they are moderately rich in carbonates and slightly depleted in Mg- and ammoniated phyllosilicates. The four families probably explain a single evolutionary path followed by the BS from the formation to their maturity: initially the very fresh bright spots would possess characteristics similar to Cerealia and Vinalia Faculae; with time, salts and $\mathrm{OH}$ volatilize and a light mixing with surrounding material would produce Oxo-like BS's; additional strong mixing would form Haulani-like BS, which finally become a typical bright spots.

\section{Introduction}

NASA's Dawn spacecraft has been orbiting around dwarf planet Ceres since March 6, 2015, acquiring multispectral images with the Framing Camera (FC) (Sierks et al., 2011), hyperspectral images using the Visible and Infrared Spectrometer (VIR) (De Sanctis et al., 2011) and maps of elemental composition by the Gamma Ray and Neutron Detector (GRaND) (Prettyman et al., 2011). Ceres is a dark object, with a geometric albedo of 0.09 at $0.55 \mu \mathrm{m}$ (Ciarniello et al., 2017), but even during the approach of Dawn, a few bright areas present on the surface were captured by FC and identified as "bright spots (BS)". The brightest spot, recognized as Cerealia Facula, lies in Occator crater, a $92 \mathrm{~km}$ in diameter depression characterized by a flat floor and a central pit on a $2 \mathrm{~km}$ wide dome. The equigonal albedo, estimated at $1.2 \mu \mathrm{m}$ under a phase angle of $30^{\circ}$ (Longobardo et al., 2017), is about 0.033 for typical Ceres surface materials. The brightest part of Cerealia Facula, coincident with the Occator central dome, shows an albedo at least 8 times larger than the Ceres average (De Sanctis et al., 2016; Longobardo et al., 2017). 
Initial compositional analysis of the Ceres surface revealed a mixture of ammoniated phyllosilicates ( $\mathrm{NH}_{4}$-montmorillonite or $\mathrm{NH}_{4}$-annite), $\mathrm{Mg}$-Ca carbonates (calcite, dolomite or magnesite), $\mathrm{Mg}$ phyllosilicates and dark material (De Sanctis et al., 2015). The presence of ammonia indicated possible exotic scenarios for the origin of the dwarf planet. Since ammonia $\left(\mathrm{NH}_{3}\right)$ can be released by the heating (at 573-673 K) of organic material (Pizzarello and Williams, 2012), ammoniated phyllosilicates could be the product of interaction between phyllosilicates and ammonia. Or, because ammonia ice has also been observed in spectra of trans-Neptunian objects,Ceres could be formed in its actual location by accretion of small objects, which originated in the outer regions of the Solar System (Johansen et al., 2015). Alternatively, and more likely, the formation of dwarf planet itself may have occurred beyond the Neptune's orbit, with Ceres migrating later to its current heliocentric distance (McKinnon, 2012) because of an orbital instability (Levison et al., 2009) or due to gravitational influence of other bodies during the formation of the giant planets (Walsh et al., 2011). The first Bright Spots analyzed in detail are those within Occator crater, i.e. Cerealia Facula and Vinalia Faculae. The first one corresponds to the crater dome, the second one lies on the crater floor. The comparison among spectra of increasing albedo in Occator crater, from the crater dark floor (analogue to Ceres mean surface) to the brightest area of the dome, highlighted a strong compositional variation, i.e. the replacement of $\mathrm{Mg}$-phyllosilicates like serpentine with more $\mathrm{Al}$ rich phyllosilicates in the brightest part of crater, the lack of ammoniated clays and a very strong increase in the carbonate abundance, as inferred by enhanced carbonate absorption bands in the brightest area of the depression (De Sanctis et al., 2016 and references therein). Furthermore, new ammoniated minerals, such as ammonium chloride or ammonium bicarbonate could be present in low abundances (De Sanctis et al., 2016). Surprisingly, Na-carbonate (e.g., natrite), which is very rare among meteorite samples present in our inventories, have been found to compose the dome of Cerealia Facula in abundances as high as 45-80 \%vol (De Sanctis et al., 2016). Ammonium chloride or ammonium bicarbonate, in addition to natrite, probably formed by precipitation of salts from brines after the impact that created Occator. 
Bright spots on Ceres are thought to be the result of phenomena like cryovolcanism (Russell et al., 2016) and post-impact hydrothermal activity (Bowling et al., 2016). In particular, simulations demonstrated the possible origin of the Occator depression by the collision of an igneous rock impactor of about $5 \mathrm{~km}$ in diameter (with a speed of $4.8 \mathrm{~km} / \mathrm{s}$ or $7.5 \mathrm{~km} / \mathrm{s}$ ) on an analogue Ceres surface (Bowling et al., 2016). The resulting depression is an $80 \mathrm{~km}$ diameter crater with a peak, formed by impact and excavation of icy-rocky material, coming from a depth of $15-30 \mathrm{~km}$ (Bowling et al., 2016). Later observations by the Dawn spacecraft allowed the discovery of many other bright spots widespread on the Ceres' surface. The first important and immediate retrieved property was that all these other features presented an albedo lower than the Occator BS's,

The main objective of this study is to perform a systematic detection of bright spots on Ceres' surface with VIR data, by retrieving not only their location but also investigating their composition by means of suitable spectral indicators. A catalogue of all the bright spots has been created and their compositional global trends by the analysis of possible differences among all of them was performed. For these purposes, we use the IR data acquired by the VIR instrument (a companion paper in this issue Stein et al., 2017, uses FC data). The following, second section of this paper describes data reduction, tools, spectral parameters and photometric correction used in the analysis. The third section explains the methodology used to create the bright spots catalogue and the general properties of the BSs. In the fourth section a statistical investigation of the general compositional trend is performed, by applying the Pearson analysis scatterplots on the most important absorption bands found in BSs spectra. Finally, in the fifth section a summary of the main results obtained in this study is given and conclusions are drafted.

\section{Tools and data reduction}

The VIR instrument consists of a single optical head, with two channels, the visible (covering the ultraviolet-visible range, i.e. $0.2-1 \mu \mathrm{m}$, with $1.8 \mathrm{~nm}$ resolution) and the infrared (1-5 $\mu \mathrm{m}$, with 9.5 
nm resolution) and produces hyperspectral data, with three dimensions, two spatial and one spectral, referred as a "image cube" (De Sanctis et al., 2011).

Our study was applied to the data obtained during all phases of the mission, characterized by different VIR nominal resolution: Approach (down to $3400 \mathrm{~m} /$ pixel), Rotation Characterization (altitude $\sim 13000 \mathrm{~km}$ and nominal resolution $\sim 3400 \mathrm{~m} /$ pixel), Survey (altitude $\sim 4400 \mathrm{~km}$ and nominal resolution $\sim 1100$ m/pixel); High Altitude Mapping Orbit (HAMO - altitude $~ 1470 \mathrm{~km}$ and nominal resolution 360-400 m/pixel); Low Altitude Mapping Orbit (LAMO - altitude $\sim 385 \mathrm{~km}$ and nominal resolution $\sim 90-110 \mathrm{~m} / \mathrm{pixel})$.

\subsection{Spectral properties of BS}

\section{BS spectral absorption features}

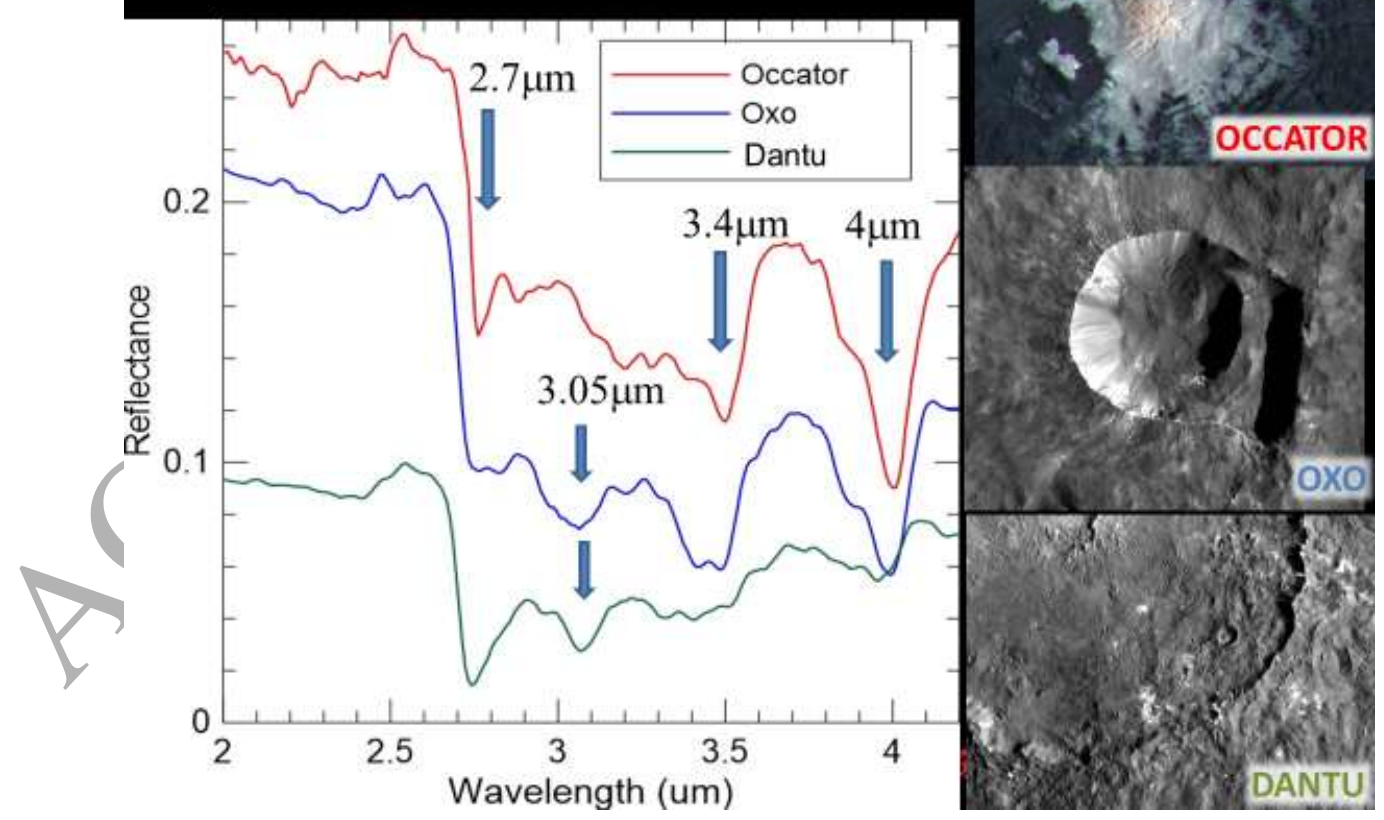

Figure 1. Three spectra of BS representing different cases: Brightest BS (Occator dome, red spectrum), Intermediate albedo BS (Oxo, blue spectrum), low albedo BS (Dantu, green spectrum). 
Figure 1 shows the spectra of three typologies of bright spots: Occator, the brightest on Ceres, Dantu, a typical BS, with a lower albedo and Oxo, having an intermediate albedo and properties between Occator and Dantu. There are four main spectral absorptions at 2.7, 3.05, 3.4 and $4.0 \mu \mathrm{m}$.

The $2.7 \mu \mathrm{m}$ feature is due to the metal hydroxide present in magnesium (Mg)-phyllosilicates (such as serpentines) (De Sanctis et al., 2015) and detected in all Ceres surface spectra with the exception of Occator, where the band center occurs at $2.76 \mu \mathrm{m}$ rather than $2.72 \mu \mathrm{m}$ (Ammannito et al., 2016), possibly indicating the occurrence of an aluminum ( $\mathrm{Al}$ )-phyllosilicate phase such as an Al-bearing smectite or illite (De Sanctis et al., 2016).

The 3.05 $\mu \mathrm{m}$ absorption band has been attributed to $\mathrm{NH}_{4}$-bearing clays (De Sanctis et al., 2015).

The last two features are attributed to the $2 \mathrm{v} 3$ overtone (i.e. the double contribution of asymmetric stretching of $\left.\mathrm{CO}_{3}{ }^{2-}\right)$ and the combination tone of the $\mathrm{v} 1+\mathrm{v} 3$ fundamentals of carbonate $(\mathrm{C}=\mathrm{O})$, respectively at $3.4 \mu \mathrm{m}$ and $4.0 \mu \mathrm{m}$ (Nuevo et al., 2014). The doublet nature (two partially overlapping absorption bands) of both of these features is consistent with carbonates. Relative depths of the 3.4 and $4.0 \mu \mathrm{m}$ features is also consistent with carbonates.

The BS spectra are quite different from each other. First of all, the reflectance level (at $1.2 \mu \mathrm{m})$ varies by a factor of 3 but the brightest pixels within a BS show reflectance values as high as 16 times larger than the lowest albedo BS. The Dantu spectrum reveals weak, but clear, carbonate bands and strong 3.05 and $2.7 \mu \mathrm{m}$ bands. The intermediate Oxo BS exhibits very strong carbonate bands and both the ammoniated phyllosilicate and the metal-OH features. However, these last bands have a different/shape from the Dantu case. In the Occator spectrum the ammoniated feature disappears, the $\mathrm{OH}$ band remains strong but becomes sharper and the carbonate bands depths increase. For the first time there is the appearance of a weaker $2.2 \mu \mathrm{m}$ spectral feature. This band is consistent with an alumimum phyllosilicate rather than a magnesium phyllosilicate (Clark et al., 1990). 


\subsection{Definitions of spectral parameters}

To study the spectral properties of bright spots and to understand the mineral composition and possibly the physical characteristics of the regolith, we introduce in our analyses spectral parameters such as band center (BC) and band depth (BD). For example, band centers are commonly used to extract compositional information, and band depths are sensitive to the abundance of surface components, regolith grain size, and the presence of opaque contaminants (Cloutis et al., 2013). Band center is defined as the band minimum after the spectral continuum removal, whereas band depth is defined as: $1-R_{b} / R_{c}$ (Clark and Roush, 1984), where $R_{b}$ and $R_{c}$ are the reflectance of the band and the spectral continuum at the BC (Gaffey et al., 2002). We removed the uncorrected artifacts present in the measured data using the method of Carrozzo et al. (2016).

The considered spectral parameters are relative to the observed main absorption bands located at $\sim 2.7, \sim 3.05, \sim 3.4$ and $\sim 4.0 \mu \mathrm{m}$. The band parameters are measured on bands defined from a detailed analysis on Ceres spectra in different mission phases (Galiano et al., 2017) and summarized below.

For the continuum, the left shoulder (short wavelength end point for continuum removal) of the 2.7 $\mu \mathrm{m}$ feature is defined as the wavelength with the maximum reflectance in the $2.63-2.70 \mu \mathrm{m}$ range, while the right shoulder (long wavelength end point for continuum removal) is defined as the maximum reflectance for a second order polynomial fit to the spectrum over the $2.8-3.0 \mu \mathrm{m}$ range. After continuum removal (defined as a straight line between the left and right shoulders), the 2.7 $\mu \mathrm{m}$ band center is obtained as the wavelength with the minimum value of reflectance between these two local maxima. For the $3.05 \mu \mathrm{m}$ band, the shoulders are calculated as wavelengths relative to local maxima of second order polynomial curves fit over the ranges $2.8-3.0 \mu \mathrm{m}$ and 3.16-3.27 $\mu \mathrm{m}$, respectively. The band center is then obtained as the wavelength corresponding to minimum reflectance after (linear) continuum removal. For the carbonate absorption bands, i.e. the absorption features near 3.4 and $4.0 \mu \mathrm{m}$, the left and right shoulders are calculated as local maxima in the ranges 3.05-3.357 and 3.55-3.68 (for the $3.4 \mu \mathrm{m}$ band) and 3.55-3.68 and 4.05-4.189 (for the 4.0 
$\mu \mathrm{m}$ feature) and the band centers as the wavelength position of the minima after (linear) continua removal.

\subsection{Photometric influences}

Vis-NIR spectra are strongly affected by illumination conditions: radiation interacts differently with regolith particles, depending on the incidence, emission or phase angles, producing different reflectances and spectral shapes and changing spectral parameters (Hapke, 1981).

Therefore a photometric correction has been applied to reflectance at the wavelengths considered for this work (i.e., at $1.2 \mu \mathrm{m}$ for absolute reflectance) and on band depths. A relation between these parameters and incidence, emission and phase angle has been retrieved by applying a statistical, semi-empirical approach, already validated on VIR Dawn data of Vesta (Longobardo et al., 2014). Equigonal albedo has been calculated by applying the Akimov disk function (Shkuratov et al., 1999), then a phase function (Longobardo et al., 2017) has been calculated and used to obtain reflectance at standard geometry (i.e. incidence $i$ of $30^{\circ}$, emission $e 0^{\circ}$ and phase angle of $30^{\circ}$ ). Analogously, the same method has been used in order to find the band depth dependence on phase angle and to retrieve their photometrically corrected values at $30^{\circ}$ phase angle.

Band centers are found to be independent of observation geometry (Longobardo et al., 2017).

\section{Bright Spot catalogue and classification}

\subsection{BS catalogue definition}

We defined Bright Spots on the Ceres' surface by adopting a relative criterion, as already done for Vesta (e.g. Pálomba et al., 2014).

Therefore, the procedure to identify a Bright Spot was the following:

- consider a single photometrically corrected reflectance VIR image, at $1.2 \mu \mathrm{m}$, and calculate its average equigonal albedo at $30^{\circ}$ phase (hereafter R30);

- $\quad$ identify pixels with R30 value greater than $30 \%$ of the cube average;

- $\quad$ if these pixels are grouped, i.e. not isolated, they would be defined as BS. 
With this definition, we could detect BS with an extension of at least 180-220 m.

This kind of definition allows classifying as bright regions even areas with albedo lower than the Ceres average but located in local darker zone, and hence probably characterized by a different origin or processing. However, these kinds of BSs are rather rare. Otherwise, regions with albedo larger than the Ceres average but located in a bright context are not considered as "Bright Spots", since they have reflectance similar to their surroundings.

By applying this procedure, we retrieved 92 Bright Spots on Ceres. For every BS we performed a classification of its geomorphology and computed its spectral indicators. Spectral parameters of a single BS are obtained as mean values of pixels which identify the BS. This allowed obtaining a complete catalogue (Table 1), similarly to what done for Vesta (Palomba et al., 2014). BSs span very different extents (from 1 to about 10 square degrees) with varying degrees of reflectance among and within some units.

\subsection{BS general properties}

Multiple observations and detections of most BS are available but only the average value for each of the BS is reported in the catalogue. Most of the units have also been detected by FC (see the "Cam" column in Table 1; see also Stein et al., 2017, this issue for an FC bright spots map).

A total of $92 \mathrm{BSs}$ with different degrees of brightness were found on Ceres spanning from 0.032 to 0.079 of equigonal albedo. Their spatial distribution (Figure 2) has no preferential orientation or aggregation, while it seems that many of them are located on younger terrains (Stein et al., 2017, this issue).

The bright spots are generally associated with spectrally blue (i.e. young) material and their parent craters also appear morphologically young: the Occator age is about 6.9 Ma, Dantu formed 46-68 Ma ago, Urvara 78 Ma ago (Nathues et al., 2016) and Oxo about $0.5 \mathrm{Ma}$ ago (Schmedemann et al., 2016). 
The larger concentration of BS is found on the Rongo and the Yalode quadrants with 11 and 17 BS, respectively. In particular Yalode is among the youngest terrains of Ceres (Ammannito et al., 2017, in preparation).

The most important bright spot complex is represented by the Occator Crater, where two wide, main spots are identified, i.e. Cerealia Facula and Vinalia Faculae, which is composed by many other minor bright spots that can be discerned especially in high spatial resolution observations (i.e. by the FC images or by VIR during the LAMO phase). These BS are the most observed in all the Dawn orbital phases, with a total of 10 and 7 VIR observations, respectively. The largest of these two BSs (Cerealia Facula) is the brightest on Ceres with an average reflectance of 0.079 , almost 3 times larger than the lowest albedo BS.

According to geomorphological characteristics, Bright Spots can be divided into 3 main families: (1) Ejecta (E); (2) Crater associated features (Crater Rims - CR, Crater Walls - CW, Crater Floors - CF, Crater Chain - CC, Crater Peak - CP or combination of these); (3) Linear features (LF). Ejecta and craters are features related to impacts. In particular, fresh craters show sharp and unmodified rims, as well as ejecta units. Linear features can be channels, crest of buried craters/crater rims, depressions or dome margins, lineaments, scarp bases or crests, and troughs (Jaumann et al., 2012). Finally, areal features include mantling material, patterned ground, secondary crater chains and hummocky terrains (Jaumann et al., 2012). The taxonomy of BS is geographically represented in Figure 2 and is dominated by the crater associated features, in particular by crater rim (about $40 \%$ of the total units) whereas the other two families, ejecta and linear features, are nearly equally represented in the BS. 


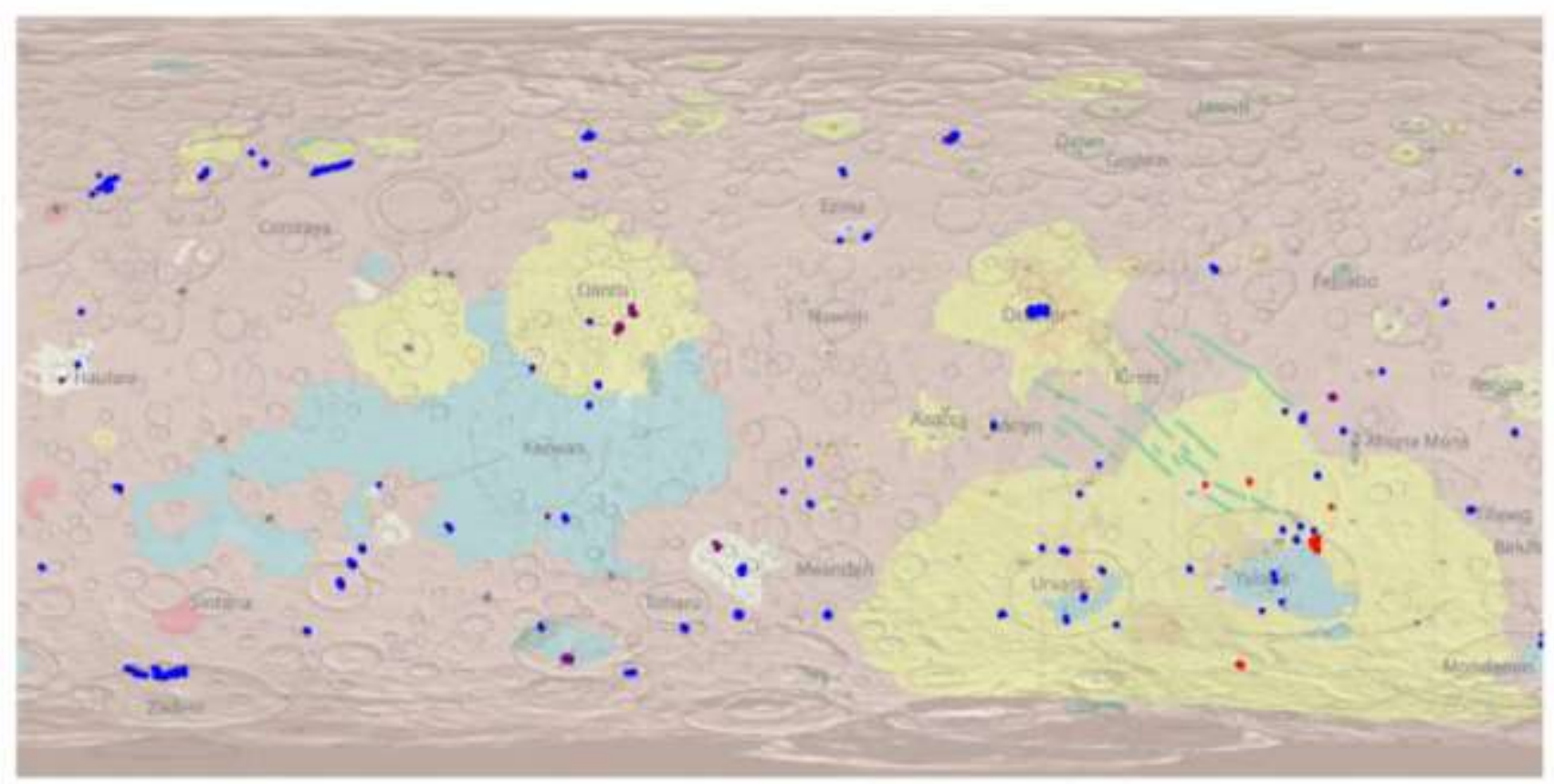

Figure 2. The distribution of Bright Spots superimposed on the geological map of Ceres. The BS are divided in 3 main families. The colors of the geological maps represent: ejecta (purple), crater associated features (blue), linear features (red).

\section{Spectral parameters: scatterplot analysis}

To better understand the relationships among different materials present in bright spots, we apply a scatterplot analysis in combination with the Pearson correlation analysis (see e.g. Palomba et al., 2015) to the four different absorption features introduced above (i.e., 2.7, 3.05, 3.4, and $4.0 \mu \mathrm{m}$ ). The Pearson coefficient measures the linear correlation between two variables and is defined as $\frac{\sigma_{\mathrm{FB}}}{\sigma_{\mathrm{F}} \sigma_{\mathrm{B}}}$, where $\sigma_{\mathrm{F}}, \sigma_{\mathrm{B}}$ and $\sigma_{\mathrm{FB}} \sigma_{\mathrm{FB}}$ are the variance of sets of e.g. the 3.4 and $4 \mu \mathrm{m}$ band depths, and their covariance, respectively. To better understand the behavior of BS in each scatterplot, we adopted different colors for their values. In particular, we defined a "typical" bright spot, which is colored in green and we colored differently all the other BSs which show peculiar properties. Moreover, two "average" values were included: the average of all the green dots to represent the BS "typical" behavior (hereafter called typical) and the Ceres average value. 


\subsection{Carbonate scatterplot analysis}

In Figure 3 the BS scatterplot of the $4.0 \mu \mathrm{m}$ band depth as function of the $3.4 \mu \mathrm{m}$ band depth is shown. Carbonate overtones band depths for typical BSs (green dots) is slightly varying with values between $0.05-0.09$ and $0.03-0.07$ for the 4.0 and the $3.4 \mathrm{BD}$, respectively. These values are similar or slightly larger than the Ceres average. Considering all the BS's we observe a clear and very strong linear trend with a Pearson coefficient of 0.744 (indicating strong correlation), with the Cerealia and the Vinalia spot having the strongest overtones observed on Ceres. There are only few BS which are considerably located away from the main cluster. One of them is represented by Ernutet, which shows a larger 3.4 band depth with respect to the $4 \mu \mathrm{m}$ one and with a different shape with respect to the $3.4 \mu \mathrm{m}$ feature of the main cluster. This is due to the presence of the organics, as recently detected by De Sanctis et al., (2017), which exhibit a well-developed $3.4 \mu \mathrm{m}$ spectroscopic feature which can contribute to increase the overall band depth. 


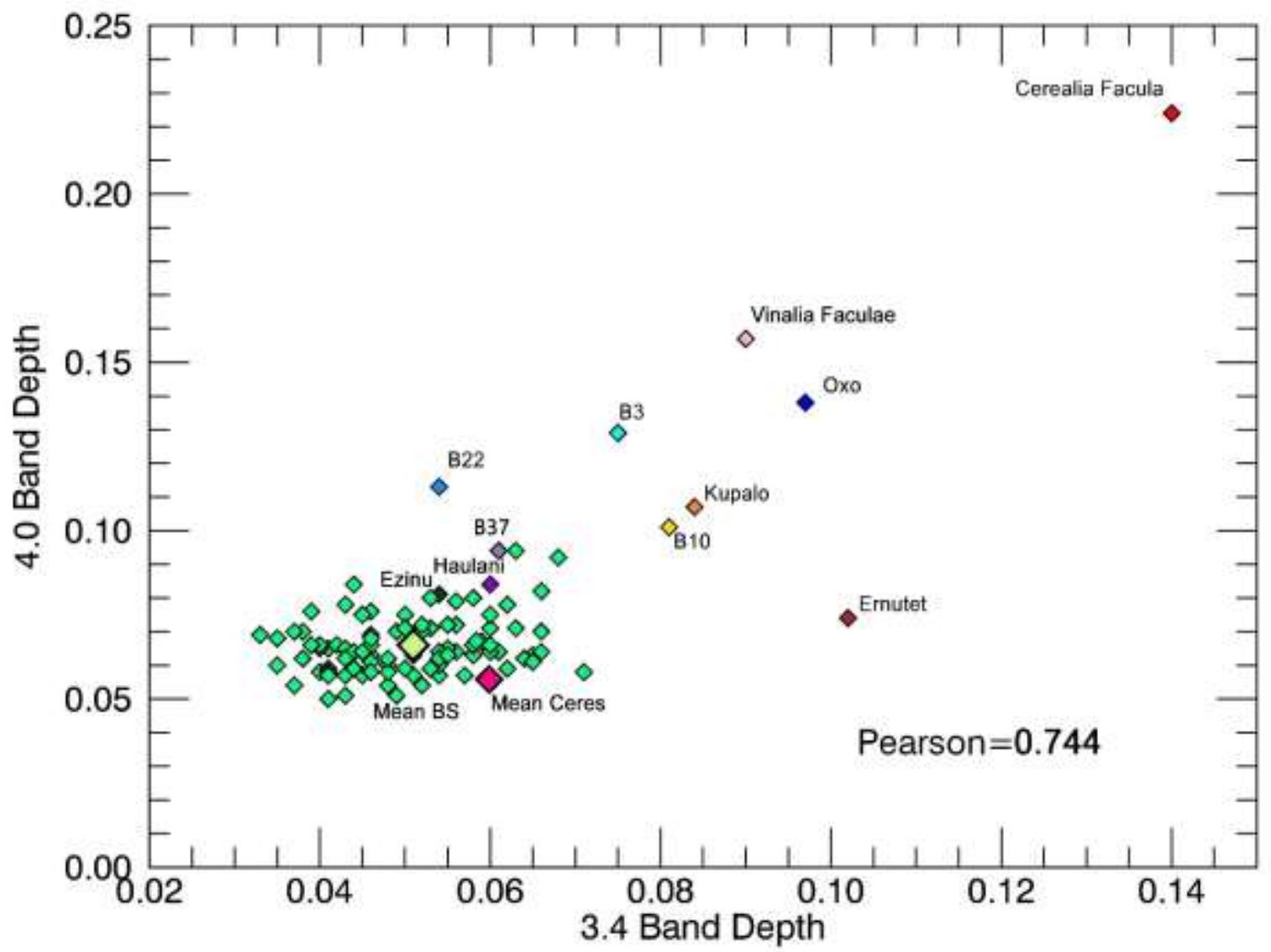

Figure 3. The scatterplot of the 4 vs the $3.4 \mu \mathrm{m}$ band depths exhibited by all the Bright Spots on Ceres. The carbonate overtone bands behave in a linear fashion. Green dots are the typical bright spots, the green yellow dot is the mean bright spot value (Mean BS), the deep pink dot is the value of average Ceres surface (Mean Ceres). The peculiar BS are represented with different colors: Cerealia Facula (red), Vinalia Faculae (pink), Oxo (dark blue), Ernutet (brown), Kupalo (orange), Haulani (purple), Ezinu (dark green), B3 (cyan), B10 (yellow), B22 (dodger blue) and B37 (slate blue).

\subsection{Carbonate vs ammoniated materials}

The $4.0 \mu \mathrm{m}$ carbonate band depths are shown in function of $3.05 \mu \mathrm{m}$ band depths in Figure 4 . Ammoniated clays which are ubiquitous on Ceres, are common in bright spots, too. The average values of the BD's are nearly coincident for typical bright spots and Ceres, (i.e. about 0.07). However, the spread among BS is large, ranging between 0.055 and 0.090 . Uniquely, the two Occator bright spots are strongly depleted in ammoniated clays, showing the lowest BD among all the BS on Ceres. The general trend including all the BS is a quite strong anti-correlation between carbonates and $\mathrm{NH}_{3}$ bearing materials, with a Pearson coefficient of -0.554 . 


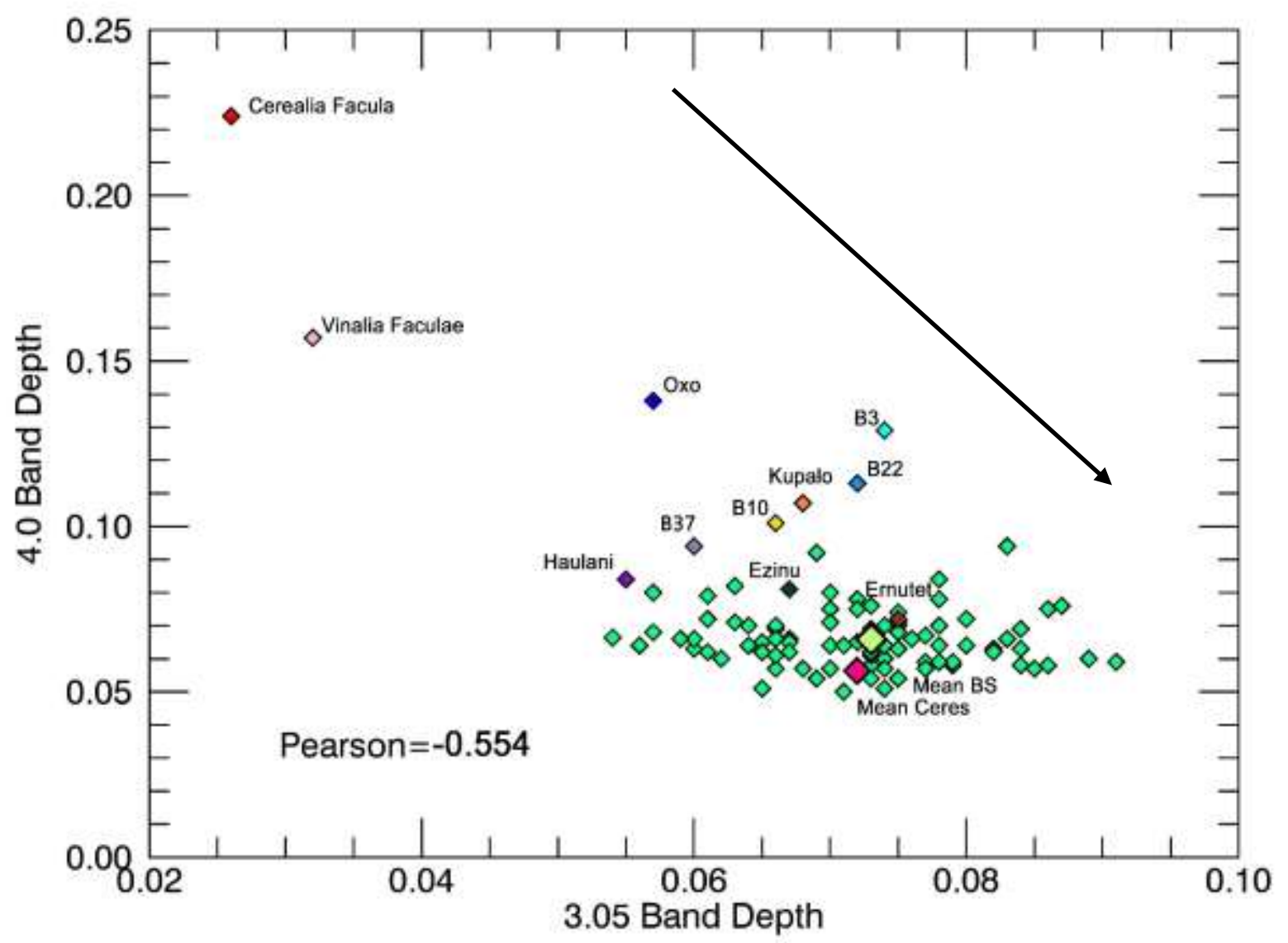

Figure 4. The scatterplot of the 4 vs the $3.05 \mu \mathrm{m}$ band depths exhibited by all the Bright Spots on Ceres. A clear anticorrelation trend is observed. Green dots are the typical bright spots, the green yellow dot is the mean bright spot value (Mean BS), the deep pink dot is the value of average Ceres surface (Mean Ceres). The peculiar BS are represented with different colors: Cerealia Facula (red), Vinalia Faculae (pink), Oxo (dark blue), Ernutet (brown), Kupalo (orange), Haulani (purple), Ezinu (dark green), B3 (cyan), B10 (yellow), B22 (dodger blue) and B37 (slate blue). The black arrow indicates the increasing ammonium/carbonate ratio.

\subsection{Carbonate vs hydrated materials}

Relative dehydration can be assessed by comparing 4.0 to $2.7 \mu \mathrm{m}$ band depths. Using this criterion, typical bright spots are dehydrated with respect to the average Ceres (Figure 5). If we do not consider Occator, the 4.0 vs $2.7 \mu \mathrm{m}$ band depth behavior shows a strong anticorrelation (Pearson coefficient of -0.680), with a clear decrease in carbonate abundance as the hydrated material abundance increases. Two trends appear to be present using these criteria. For the main cluster plus Oxo and B3, Oxo and B3 are among the less hydrated and carbonate-rich BSs. A different trend 
arises, instead, if Vinalia and Cerealia Faculae are included. Now the trend follows a different path with respect to the other BSs and exhibits a moderately strong 2.7 band, comparable with carbonate poorer BSs. A possible explanation of the Occator unique trend can be found in the different nature of hydrated materials present on Occator, where Al-phyllosilicates are present instead of the $\mathrm{Mg}$ phyllosilicates that are common on the rest of the BSs. The presence of Al-phyllosilicates is confirmed by the presence of a $2.2 \mu \mathrm{m}$ absorption band and the position of the $2.7 \mu \mathrm{m}$ absorption feature being present at longer wavelengths (closer to $2.76 \mu \mathrm{m}$ ).

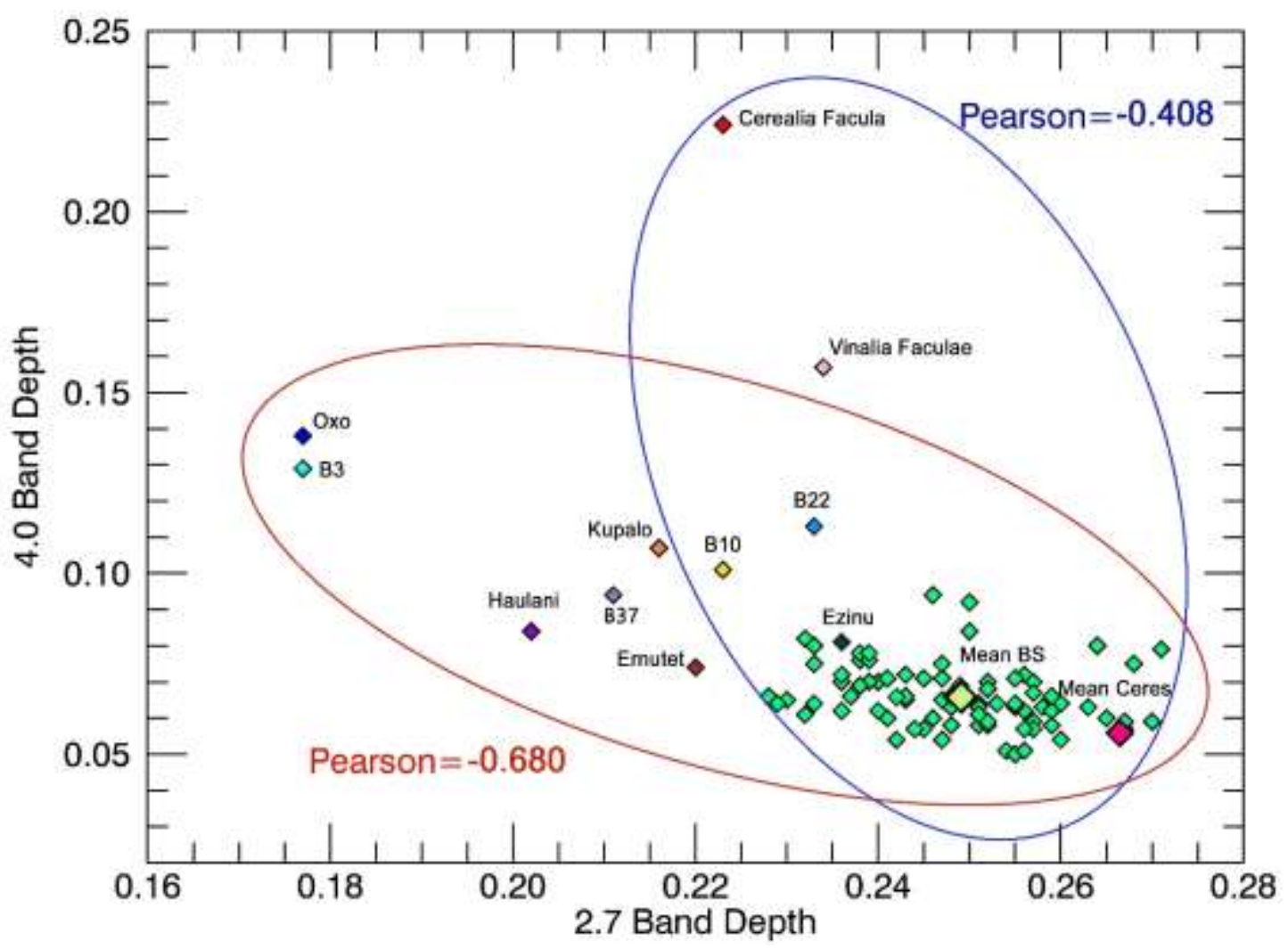

Figure 5. The scatterplot of the 4 vs the $2.7 \mu \mathrm{m}$ band depths exhibited by all the Bright Spots on Ceres. A clear anticorrelation behavior is observed. Occator follows a different trend. Green dots are the typical bright spots, the green yellow dot is the mean bright spot value (Mean BS), the deep pink dot is the value of average Ceres surface (Mean Ceres). The peculiar BS are represented with different colors: Cerealia Facula (red), Vinalia Faculae (pink), Oxo (dark blue), Ernutet (brown), Kupalo (orange), Haulani (purple), Ezinu (dark green), B3 (cyan), B10 (yellow), B22 (dodger blue), and B37 (slate blue). 


\subsection{Ammoniated vs hydrated compounds}

Similarly to the overall Ceres behavior (Ammanito et al., 2016), there is a moderate linear correlation for the $2.7 \mathrm{vs} 3.05 \mu \mathrm{m}$ band depth scatterplot (Figure 6). A dehydration of the average typical BS with respect to the average Ceres is present, but the ammoniated clays are present in similar amounts, showing similar band depths. However, besides the most populated bright spot group (green dots) which show a positive relationship with band depths, there are apparently two other small BS groups which show opposite characteristics. The first one, represented by B3 and Oxo, is depleted in $\mathrm{OH}$, implying lower phyllosilicate content. The second group, represented by the Occator BSs, is instead depleted in ammoniated clays. Another group, including Kupalo, B37 and Haulani, continues the trend of decreasing 2.7 and $3.05 \mu \mathrm{m}$ band depths.

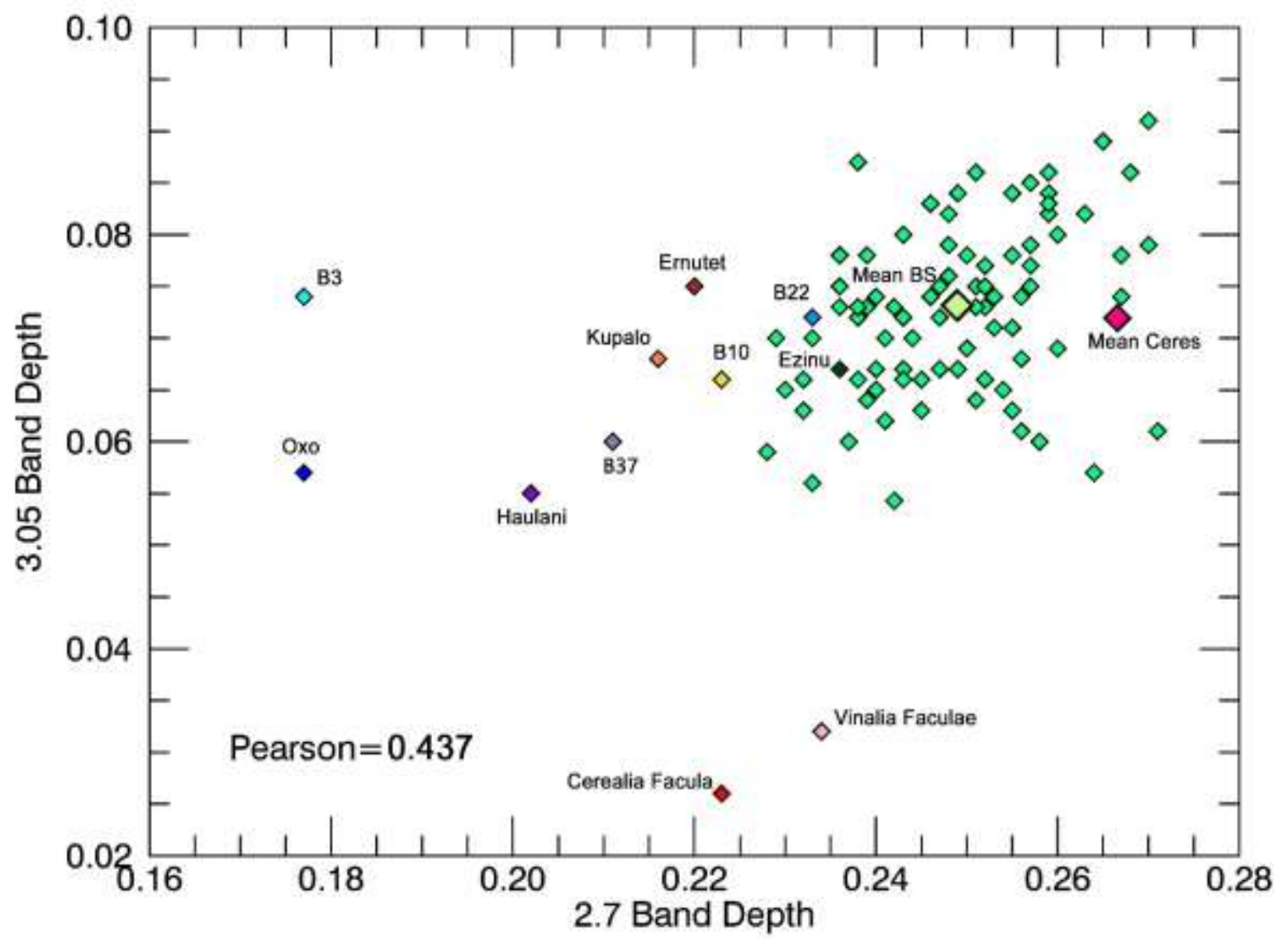

Figure 6. The scatterplot of the 3.05 vs the $2.7 \mu \mathrm{m}$ band depths exhibited by all the Bright Spots on Ceres. A clear anticorrelation behavior is observed among all BS, excluding Occator BS which follows a unique trend. Green dots are the typical bright spots, the green yellow dot is the mean bright spot value (Mean BS), the deep pink dot is the value of average Ceres surface (Mean Ceres). The peculiar BS are represented with different colors: Cerealia Facula (red), 
Vinalia Faculae (pink), Oxo (dark blue), Ernutet (brown), Kupalo (orange), Haulani (purple), Ezinu (dark green), B3 (cyan), B10 (yellow), B22 (dodger blue) and B37 (slate blue).

\subsection{Carbonate composition}

In Figure 7, all the BS's R30 values are plotted as function of the $4 \mu \mathrm{m}$ carbonate band center. The latter is indicative of the carbonate composition: $4.011 \mu \mathrm{m}$ is the band center in sodium carbonates whereas 3.979 and $3.943 \mu \mathrm{m}$ are the band center for calcium and magnesium carbonates, respectively. The band center of dolomite, a carbonate of calcium and magnesium, is at $3.958 \mu \mathrm{m}$. The typical bright spot has the same carbonate composition of the average Ceres and is about $50 \%$ brighter. In particular, as observed in the scatterplot $4.0 \mu \mathrm{m}$ band depth in function of $3.4 \mu \mathrm{m}$ band depth, the carbonate absorption features of typical bright spot vary of about $1 \%$ with respect to the average Ceres. As pointed out in the previous section there are few bright spots that are "darker" than the Ceres average and this is a consequence of the relative definition we adopted.

There is no strong correlation between band centers and brightness, but a clear shift of the $\mathrm{BC}$ from $\mathrm{Mg}-\mathrm{Ca}$ to $\mathrm{Na}$ carbonates is observed in Occator. The majority of BSs are Mg-Ca carbonate-rich, similarly to average Ceres. However there are few locations with very clear Na compositions apart from Occator, particularly Oxo, Kupalo and B3. 


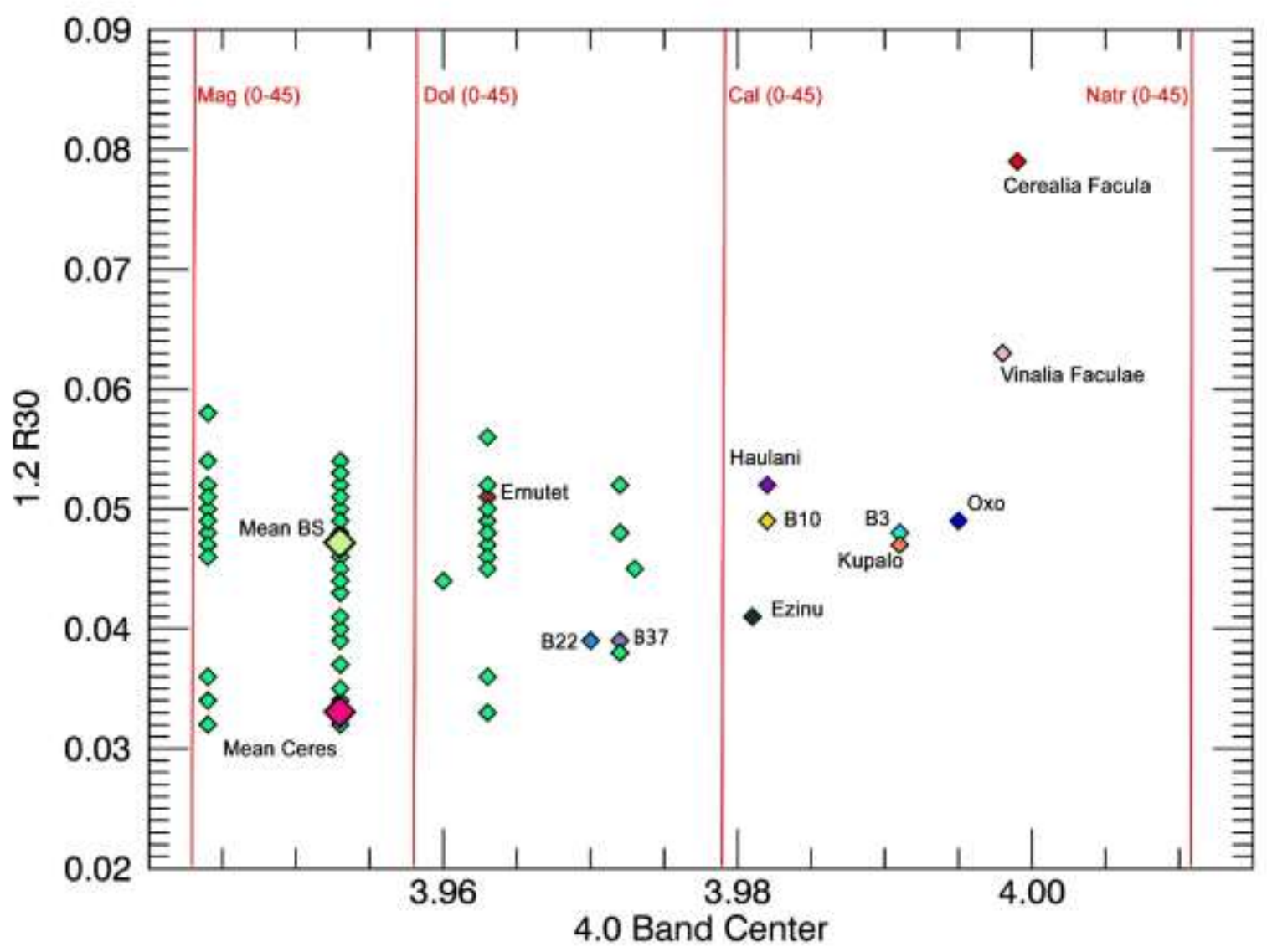

Figure 7. The scatterplot shows the $4.0 \mu \mathrm{m}$ band center vs reflectance. BS with band centers of $4.0 \mu \mathrm{m}$ feature located at longer wavelengths are indicative of a mixture containing $\mathrm{Na}$-carbonate, with respect to the average $\mathrm{BS}$, whose carbonate endmember is Mg-Ca. BC of Magnesite, Dolomite, Calcite and Natrite with grain size $(0-45 \mu \mathrm{m})$ are indicated with vertical red straight lines, respectively at $3.943 \mu \mathrm{m}, 3.958 \mu \mathrm{m}, 3.979 \mu \mathrm{m}$ and $4.011 \mu \mathrm{m}$ (spectra acquired by RELAB database). Green dots are the typical bright spots, the green yellow dot is the mean bright spot value (Mean BS), the deep pink dot is the value of average Ceres surface (Mean Ceres). The peculiar BS are represented with different colors: Cerealia Facula (red), Vinalia Faculae (pink), Oxo (dark blue), Ernutet (brown), Kupalo (orange), Haulani (purple), Ezinu (dark green), B3 (cyan), B10 (yellow), B22 (dodger blue) and B37 (slate blue).

\subsection{Unusual Bright Spots}

In this sub-section, we provide an overview of few BSs which show very particular spectral behaviors. However, since the spectral parameters of BS are obtained as mean values of pixels which identify the BS, compositional variations within individual bright spots are possible. 
In all the previously discussed scatterplots the peculiar bright spots have been highlighted with colours other than green and show distinct differences from the typical bright spots. Many of them have already captured the attention of other researchers and are the target of more detailed investigations (i.e. Occator, Haulani, Oxo) but we believe that others deserve an individual and more focused study in the future.

- $\quad$ B3 $\left(60-62^{\circ} \mathrm{N}, 220-222^{\circ} \mathrm{E}\right)$ is a bright unit located in Ezinu quadrangle (AC-H-4) on the rim of a young, small crater in a background of cratered terrain, the oldest Ceres geological unit with a Lunar-derived absolute Model Age of 3380+110/-310 Ma and an Asteroid-Fluxderived absolute Model Age of 4120+250/-530 Ma (Scully et al., 2016). This cratered terrain formed during Pre-Kerwanan period (Wagneret al., 2016). Small impact craters on Ceres are more easily altered by regolith with respect to larger basins (Scully et al., 2016) and consequently their spectra are influenced by background spectral values; therefore, the presence of bright material as ejecta or on the rim of small craters is likely of recent origin. This BS is one of the brightest, with a R30 value of 0.048 , and shows very large carbonate overtone band depths. The band center of the $4 \mu \mathrm{m}$ feature is located at 3.99 , with absorption band centers between the values of $\mathrm{Na}$ carbonates and $\mathrm{Ca}$ carbonates. Similar to Oxo and in contrast with the general BSs trend, the large abundance of carbonates is associated with a large abundance of the $\mathrm{NH}_{4}$ bearing clays. It is also the most $\mathrm{OH}$ depleted bright spot on Ceres.

- $\mathrm{Oxo}\left(42-43^{\circ} \mathrm{N}, 359 / 0^{\circ} \mathrm{E}\right)$ is a $10 \mathrm{~km}$ diameter crater where spectral features at $1.65 \mu \mathrm{m}$ and $2.0 \mu \mathrm{m}$ were detected in localized areas, suggesting the presence of water ice or hydrated minerals (Combe et al., 2016). The Oxo BS involves bright material on the crater wall and in ejecta, corresponding to a fresh unit probably formed during the youngest Cerean period (Hughson et al., 2016). The areas where hydrated minerals have been detected are not part of Oxo BS. Oxo shares similar properties with B3: they are both $\mathrm{OH}$ depleted and $\mathrm{NH}_{4}$ 
bearing clay-rich. The carbonate composition is similar. Even if they are far from one another, it seems that their origin or maybe the processes that evolved them to their present state could have been similar.

- $\mathrm{B} 10\left(52-53^{\circ} \mathrm{N}, 354-355^{\circ} \mathrm{E}\right)$ and Kupalo $\left(40-42^{\circ} \mathrm{S}, 170-172^{\circ} \mathrm{E}\right)$. B10 is a bright unit located on a crater wall in the Fejokoo Quadrangle. It is the result of a recent impact crater which, as mentioned, can be easily altered over time (Hughson et al., 2016). Kupalo is located in the Toharu Quadrangle and the bright unit is relative to the crater wall of the $26-\mathrm{km}$ diameter depression. They share common properties and are among the most carbonate-rich BS with a composition pointing towards a possible mixture of $\mathrm{Na}$ and $\mathrm{Ca}$ endmembers. With respect to the typical BS behavior, they are depleted in $\mathrm{OH}$ phyllosilicates and show an average abundance of ammoniated clays.

- The Ezinu BS $\left(36-39^{\circ} \mathrm{N}, 194-202^{\circ} \mathrm{E}\right)$ is a bright unit on the rim of a crater with the same name. The $110.5 \mathrm{~km}$ diameter crater probably formed in the Ceres oldest period (more than $200 \mathrm{Ma}$ ago), with a minimum lunar-derived absolute model age of $968 \pm 76 \mathrm{Ma}$ and a minimum asteroid-flux-derived absolute model age of 257 $\pm 13 \mathrm{Ma}$ (Scully et al., 2016). BSs are generally connected with recent phenomena, but some of them probably formed earlier and darkened as a consequence of mixing with other materials on Ceres' surface (Scully et al., 2016; Stein et al., this issue). Such darkening could have occurred for the Ezinu BS, since it is characterized by lower reflectance with respect to the mean BS and shows band depths similar to other bright spots. The real important characteristic which makes it of interest is the location of the $4.0 \mu \mathrm{m}$ band center at a position indicative of Ca carbonates, or a higher abundance of Na-carbonates in a mixture with Mg-carbonates, in contrast to the average BSs that are more shifted to magnesium or calcium-magnesium endmembers.

- Cerealia Facula $\left(19-21^{\circ} \mathrm{N}, 238-240^{\circ} \mathrm{E}\right)$ and Vinalia Faculae $\left(19-21^{\circ} \mathrm{N}, 241-243^{\circ} \mathrm{E}\right)$ are bright spots located respectively in the dome and on the crater floor of Occator, a $92 \mathrm{~km}$ diameter crater located in the homonymous Quadrangle, which probably formed during the 
intermediate period or at the beginning of young period (Scully et al., 2016). Cerealia Facula and Vinalia Faculae are the two most prominent bright units in the Occator depression and are recent formations that probably emerged from the subsurface after impact and flowed across the crater floor until the youngest age (Scully et al., 2016), the Urvaran period (Wagner et al., 2016). Cerealia and Vinalia Faculae are unique features among all the BS. They are the richest in carbonates and are depleted in $\mathrm{NH}_{4}$ - bearing phases (e.g. clays or salts). Carbonates are Na-rich and $\mathrm{OH}$ is well present, exhibiting a band depth similar to the darkest BSs, but associated with more Al-enriched phyllosilicates.

- The Haulani BS corresponds to the southern ejecta, located at $3-5^{\circ} \mathrm{N}$ and $10-11^{\circ} \mathrm{E}$, of the 34 $\mathrm{km}$ diameter Haulani crater located in the homonymous quadrangle. Such ejecta are made of very fresh and fine-grained smooth material, where flow structures and channels are also visible (Krohn et al., 2016). Haulani is one of the youngest features on Ceres, whose formation occurred 1.67 \pm 0.28 Ma following the Asteroid Flux Model Age or 1.96 $\pm 0.17 \mathrm{Ma}$ in the Lunar-derived Model Age (Krohn et al., 2016) and therefore belonging to the Urvaran period (Wagner et al., 2016), As a consequence of the impact, an ice-rich layer probably emerged from the subsurface and was exposed as ejecta. If ice-rich, the surface layer would be unstable against sublimation, generating fractures and depressions inside and around Haulani crater (Krohnet al., 2016; Sizemore et al., 2017). Haulani has an average to slightly higher carbonate abundance with respect to the other BSs. It is largely depleted in $\mathrm{OH}$ and has a lower abundance of $\mathrm{NH}_{4}$ clays. The carbonate composition points toward a calciumrich endmember or a greater than average Na-carbonate abundance.

- $\quad$ B $37\left(10-12^{\circ} \mathrm{S}, 311-312^{\circ} \mathrm{E}\right)$ is a bright area in the Rongo Quadrangle. The reduced 2.7 and $3.05 \mu \mathrm{m}$ band depths suggest a depletion of hydrated minerals and a lower abundance of ammoniated phyllosilicates. The large $4.0 \mu \mathrm{m}$ band depth suggests a higher abundance of carbonate with respect to the average BS. The band center position (about $3.97 \mu \mathrm{m}$ ) indicates a $\mathrm{Mg}$-Ca carbonate composition. 
- $\mathrm{B} 22\left(15-17^{\circ} \mathrm{N}, 141-143^{\circ} \mathrm{E}\right)$ is a bright unit related to ejecta of Dantu, a $126-\mathrm{km}$ diameter crater. It is rich in $\mathrm{Mg}-\mathrm{Ca}$ carbonates because of a deep $4.0 \mu \mathrm{m}$ band depth. It is lightly hydrated, while the abundance of ammoniated phyllosilicates is comparable to the average BS.

- Ernutet BS $\left(51-54^{\circ} \mathrm{N}, 43-45^{\circ} \mathrm{E}\right)$ is related to the peak of a $53.4 \mathrm{~km}$ diameter homonymous crater located in the Coniraya Quadrangle. On the floor, on the southern and northwest rims and in the proximal ejecta of crater, aliphatic organics have been detected (De Sanctis et al., 2017). The Ernutet BS is OH depleted, while the abundance of carbonates and ammoniated phyllosilicates are comparable with average BS values. The position of $4.0 \mu \mathrm{m}$ band center is indicative of an $\mathrm{Mg}$-Ca carbonates endmember.

\section{Conclusions}

In this work, bright spots located on the Ceres surface have been detected by applying a relative reflectance criterion, i.e., areas showing a reflectance larger than the surroundings. A catalogue of BSs that includes 92 spots has been compiled. Most (90\%) of the BSs are associated with impactrelated features, i.e., ejecta or craters (rim, floor or wall). The BS's are randomly distributed on Ceres, at slightly larger concentration within the Rongo and the Yalode quadrants and with a possible relation with the youngest age terrains. The average brightness varies among the BSs, with the Occator spots being up to 3 times brighter than the BS with lowest albedo.

The spectral properties of the BS were examined after applying a photometric correction of the parameters such as reflectance, band depths (carbonate, $\mathrm{OH}$, ammoniated bearing clays) and band centers. The bright spots present on Ceres' surface vary in compositional properties. Most of them (termed typical BSs), have similar characteristics to the average Ceres surface: low absolute reflectance, low carbonate abundance with $\mathrm{Ca}-\mathrm{Mg}$ composition and the presence of ammoniated clays. However, there are few BSs with peculiar behaviors, with the best example given by the Occator bright spots, which include the Cerealia and Vinalia Faculae, both located in the Occator 
crater. These BSs have a clear and distinct trend from all the other bright spots on Ceres. They are the brightest spots on Ceres and have the greatest abundance of carbonates (i.e. the carbonate overtones are strongest). The composition of carbonates is sodium-rich and they appear to be more $\mathrm{OH}-$ rich with respect to other carbonate-rich BS. Their phyllosilicates are also of a different nature, being $\mathrm{Al}$ rather than $\mathrm{Mg}$ bearing. A third typology is represented by the Oxo group, formed by Oxo and the B3 bright spots. This group is characterized by a moderate to high albedo BS and it shows important differences with respect to the typical BS main group family: they appear to be depleted in $\mathrm{OH}$ - and $\mathrm{NH}_{4}$-bearing compounds and their carbonate composition changes from $\mathrm{Mg} / \mathrm{Ca}$, common in all the Ceres surface, to $\mathrm{Na}$ or a mixture of the two. A fourth group encompasses Haulani, Ernutet, Kupalo, B3, B37 and B10. They have intermediate properties between the typical bright spots and the Occator or the Oxo groups: moderately rich in carbonates with the composition encompassing all the observed endmembers on BSs, moderately depleted in $\mathrm{OH}$ and slightly depleted in ammoniated clays. An important question arises from the analysis here presented. The two most peculiar bright spot groups (Occator and Oxo) share strong commonalities about both the carbonate composition and abundance and let us suggest a similar formation process or evolutionary path. However, these similarities are not shared when considering $\mathrm{OH}$ absorption band depth. The Oxo group has the weakest $\mathrm{OH}$ band depth while Occator's is strong. Apart from Occator, we observe among the BSs a clear and progressive dehydration as carbonate abundance becomes more and more important. The last points of this process are Oxo and B3. Then, Vinalia Faculae, which shares similar carbonate band strength with Oxo, is more hydrated. Interestingly, Cerealia Facula, which has a stronger carbonate band, shows again a weaker $\mathrm{OH}$ band with respect to Vinalia, mimicking the trend observed for all the other BSs.

Therefore, Oxo and B3 seems to be characterized by a carbonate abundance similar to Occator BS but with an opposite hydration behavior. A strong correlation between carbonates and phyllosilicates is observed considering typical BS, Oxo and B3 but the band center of $4.0 \mu \mathrm{m}$ band 
suggests a different carbonatic mineralogy. The carbonates present in Oxo and B3 are probably a mixture of $\mathrm{Na}-\mathrm{Ca}$ carbonates, while a combination of $\mathrm{Mg}-\mathrm{Ca}$ carbonates is likely in typical BS. Since many bright spots are related to younger terrains, the effect of space weathering could be minimal and probably just the mixing could be performed (Steins et al., 2017).

Each bright spot could have followed a single evolutionary path: starting from a Cerealia like bright spot and finally evolving to a typical Ceres bright spot. Initially, the very fresh bright spots will have a composition similar to Cerealia and Vinalia facula, with a very high $\mathrm{Na}$ carbonate abundance, ammoniated salts and dark compounds. The volatilization of salts and $\mathrm{OH}$ and a weak mixing will allow the gradual loss of $\mathrm{Na}$ carbonate abundance and the addition of $\mathrm{Mg}$ phyllosilicates mixed with dark material. The bright spots, at this state, will be more similar to Oxo and B3. Finally, a strong mixing will generate the typical bright spots, with ammoniated clays, Mgphyllosilicates, dark compounds and low $\mathrm{Mg}-\mathrm{Ca}$ carbonate ábundance.

Our results highlight that the bright spots on Ceres show not only different spectral, and consequently compositional, properties but they even suggest evolutionary process involved in their differentiation.

\section{Acknowledgements}

VIR is funded by the Italian Space Agency-ASI and was developed under the leadership of INAFIstituto di Astrofisica e Planetologia Spaziali, Rome-Italy. The instrument was built by SelexGalileo, Florence-Italy. The authors acknowledge the support of the Dawn Science, Instrument, and Operations Teams. This work was supported by ASI and NASA. 


\section{Reference}

Ammannito, E. et al., 2016, Distribution of phyllosilicates on the surface of Ceres, Science 353 (6303).

Beran, A., 2002, Crystal Chemistry and Metamorphic Petrology, in Micas, eds Mottana, A., Sassi, F. P., Thompson, J. B. and Guggenheim, S., Mineralogical Society of America, pp. 351-370.

Bishop, J. L., Lane, M. D., Dyar, M. D. and Brown, A. J., 2008, Reflectance and emission spectroscopy study of four groups of phyllosilicates: smectites, kaolinite-serpentines, chlorites and micas, Clay Minerals, 43, pp. 35-54.

Bowling, T. J., Ciesla, F. J., Marchi, S., Johnson, B. C., Davison, T. M., Castillo-Rogez, J. C., De Sanctis, M. C., Raymond, C. A. and Russell., C. T., 2016, Impact induced heating of Occator crater on asteroid 1 Ceres, 47th Lunar and Planetary Science Conference.

Carrozzo, F. G., Raponi, A., De Sanctis, M. C., Ammannito, E., Giardino, M., D’Aversa, E., Fonte, S. and Tosi, F., 2016, Artifacts reduction in VIR/Dawn data, Review of Scientific Instruments, 87 (12), 124501.

Clark, R. N. and Roush T.L., 1984, Reflectance spectroscopy: quantitative analysis techniques for remote sensing applications, Journal of Geophysical Research 89 (B7), pp.632-6340.

Clark, R. N., Swayze, G. A., Singer, R. B. and Pollack, J. B., 1990, High-Resolution Reflectance Spectra of Mars in the 2.3-/am Region: Evidence for the Mineral Scapolite, Journal of Geophysical Research 95 (B9), pp.14463-14480.

Cloutis, E. A., Izawa, M. R. M., Pompilio, L., Reddy, V., Hiesinger, H., Nathues, A., Mann, P., Le Corre, L., Palomba, E. and Bell, J. F., 2013, Spectral reflectance properties of HED meteorites + 
CM2 carbonaceous chondrites: Comparison to HED grain size and compositional variations and implications for the nature of low-albedo features on Asteroid 4 Vesta, Icarus 223 (2), pp. 850-877.

Combe, J.-P., McCord, T. B., Tosi, F., Ammannito, E., Carrozzo, F. G., De Sanctis, M. C., Raponi, A., Byrne, S., Landis, M. E., Hughson, K. H. G., Raymond, C. A. and Russel, C. T., 2016, Detection of local $\mathrm{H}_{2} \mathrm{O}$ exposed at the surface of Ceres, Science 353 (6303), pp.1-6.

De Sanctis, M.C., Coradini, A., Ammannito, E., Filacchione, G., Capria, M. T., Fonte, S., Magni, G., Barbis, A., Bini, A., Dami, M., Ficai-Veltroni, I., Preti, G. and the VIR Team, 2011, The VIR spectrometer, Space Science Reviews, 163 (1-4), pp. 329-369.

De Sanctis, M.C. et al., 2015, Ammoniated phyllosilicates with a likely outer Solar System origin on (1) Ceres, Nature 528 (7581), pp. 241-244.

De Sanctis, M.C. et al., 2016, Bright carbonate deposits as evidence of aqueous alteration on (1) Ceres, Nature 536, pp. 54-57.

Gaffey, M. J., Cloutis, E. A., Kelly, M. S., Reed, K. L., 2001, Mineralogy of asteroids, in Asteroids III, eds Bottke Jr, W. F., Cellino, A., Paolicchi, P., and Binzel, R. P., University of Arizona Press, Tucson, p.183-204.

Galiano, A., Palomba, E., Longobardo, A., Zinzi, A., De Sanctis, M. C., Raponi, A., Carrozzo, F. G., Ciarniello, M and Dirri, F., 2017, Continuum definition for $\sim 3.1, \sim 3.4$ and $\sim 4.0 \mu \mathrm{m}$ absorption bands in Ceres spectra and evaluation of effects of smoothing procedure in the retrieved spectral parameters, submitted to Advances in Space Reasearch.

Hapke, B, 1981, Bidirectional reflectance spectroscopy: 1. Theory, Journal of Geophysical Research 86, pp. 3039-3054. 
Hughson, K. H. G., Russell, C. T., Williams, D. A., Buczkowski, D. L., Mest, S. C., Pasckert, J. H., Scully, J. E. C., Combe, J.-P., Platz, T., Ruesch, O., Preusker, F., Jaumann, R., Nass, A., Roatsch, T., Nathues, A., Schaefer, M., Schmidt, B. E., Chilton, H. T., Ermakov, A. and McFadden, L. A., 2016, The Ac-H-5 (Fejokoo) quadrangle of Ceres: Geologic map and geomorphological evidence for ground ice mediated surface processes, submitted to Icarus.

Jaumann, R. et al., 2012, Vesta's shape and morphology, Science 336 (6082), pp. 687-690.

Jaumann, R., Nass, A., Otto, K., Krohn, K., McCord, T.B., Williams, D.A., Raymond, C.A., Stephan, K., Blewett, D.T., Hiesinger, H., Yingst, R.A., DeSanctis, M.C., Palomba, E., Roatsch, T., Matz, K.-D., Russell, C.T., 2014, The geological nature of dark material on Vesta and implications for the subsurface structure, Icarus 240, pp. 3-19.

Johansen, A., Mac Low, M.-M., Lacerda, P. and Bizzarro, M., 2015, Growth of asteroids, planetary embryos, and Kuiper belt objects by chondrule accretion., Science Advances 1 (3), e1500109.

Krohn K. et al., 2016, The unique geomorphology and structural geology of the Haulani crater of 1 dwarf planet Ceres as revealed by geological mapping of equatorial quadrangle Ac-6 Haulani, submitted to Icarus.

Levison, H. F., Bottke, W. F., Gounelle, M., Morbidelli, A., Nesvorny, D. and Tsiganis, K., 2009, Contamination of the asteroid belt by primordial trans-Neptunian objects, Nature 460, pp. 364-366.

Longobardo, A., Palomba, E., Capaccioni, F., De Sanctis, M. C., Tosi, F., Ammannito, E., Schröder, S. E., Zambon, F., Raymond, C. A. and Russell, C. T., 2014, Photometric behavior of spectral parameters in Vesta dark and bright regions as inferred by the Dawn VIR spectrometer, Icarus 240, pp. 20-35. 
Longobardo, A., Palomba, E., Galiano, A., De Sanctis, M. C., Ciarniello, M., Raponi, A., Tosi, F., Schröder, S. E., Carrozzo, F. G., Ammannito, E., Zambon, F., Stephan, K., Capria, M. T., Rognini, E., Raymond, C. A. and Russell, C. T., 2017, Photometry of Ceres and Occator faculae as inferred from VIR/Dawn data, submitted to Icarus.

McCord, T.B. et al., 2012. Dark material on Vesta from the infall of carbonaceous volatile-rich material, Nature 7422 (491), pp.83-86.

McKinnon, W. B., 2012, Where did Ceres accrete?, In Proceedings of the Conference Asteroids, Comets, Meteors 2012, abstr. 6475, http://www.lpi.usra.edu/meetings/acm2012/pdf/6475.pdf.

Nathues, A. et al., 2016, FC color images of dwarf planet Ceres reveal a complicated geological history, Planetary and Space Science 134, pp. 122-127.

Nuevo, M., Sandford, S.A., Flynn, G.J. and Wirick, S., 2014, Mid-infrared study of stones from the Sutter's Mill meteorite, Meteoritics \& Planetary Science 49 (11), pp. 2017-2026.

Palomba, E., Longobardo, A., De Sanctis, M. C., Zambon, F., Tosi, F., Ammannito, E., Capaccioni, F., Frigeri, A., Capria, M. T., Cloutis, E. A., Jaumann, R., Combe, J.-P., Raymond, C. A. and Russell, C. T., 2014, Composition and mineralogy of dark material units on Vesta, 240, p. 58-72

Palomba, E., Longobardo, A., De Sanctis, M. C., Zinzi, A., Ammannito, E., Marchi, S., Tosi, F., Zambon, F., Capria, M. T., Russell, C. T., Raymond, C. A. and Cloutis, E. A., 2015, Detection of new olivine-rich locations on Vesta, Icarus, 258, 120-134

Palomba, E., Longobardo, A., De Sanctis, M. C., Ammannito, E., Carrozzo, F. G., Raponi, A., Ciarniello, M., Frigeri, A., Capria, M. T., Tosi, F., Zambon, F., Fonte, S., Giardino, M., Capaccioni, F., Pieters, C. M., Raymond, C. A., Russell, C. T. and the Dawn Science Team, 2016, Compositional characteristic of Ceres Bright Spots, 47th Lunar and Planetary Science Conference. 
Pizzarello, S. and Williams, L. B., 2012, Ammonia in the early Solar System: an account from carbonaceous meteorites, Astrophysycal Journal 749 (2), pp. 161-167.

Russell, C.T., 2016, Dawn arrives at Ceres: Exploration of a small volatile-rich world, 47th Lunar and Planetary Science Conference.

Schmedemann N., Kneissl, T., Neesemann, A., Stephan, K., Jaumann, R., Krohn, K., Michael, G. G., Matz, K. D., Otto, K. A., Raymond, C. A. and Russell, C. T., et al., 2016, Timing of optical maturation of recently exposed material on Ceres, Geophysical. Research Letters 43, pp.1198711993.

Schröder, S.E., Mottola, S., Keller, H. U., Raymond, C. A. and Russell, C. T., 2013, Resolved photometry of Vesta reveals physical properties of crater regolith, Planetary and Space Science 85, pp. 198-213.

Scully, J. E. C. et al., 2016, The localized distribution of water ice on Ceres, as evidenced by geologic mapping of the northern-mid-latitude Ezinu quadrangle, submitted to Icarus.

Sizemore, H.G., Platz, T., Schorghofer, N., Crown, D. A., Prettyman, T. H., De Sanctis, M. C., Buczkowski, D. L., Hughson, K. H. G., Marchi, S., Mest, S. C., Williams, D. A., Schenk, P. M., Bland, M. T., Schmidt, B. E., Chilton, H. T., Russell, C. T., Raymond, C. A. and the Dawn Science Team, 2017, Ceres' Pitted Terrains: Morphological Context and Implications for Ground Ice, 48th Lunar and Planetary Science Conference.

Stein, N. et al., Characteristics, Formation, and Evolution of Faculae (Bright Spots) on Ceres, submitted to Icarus, this special issue.

Wagner, R. J., Schmedemann, N., Stephan, K., Jaumann, R., Kneissl, T., Neesemann, A., Krohn, K., Otto, K., Preusker, F., Kersten, E., Roatsch, T., Hiesinger, H., Williams, D. A., Yingst, R. A., 
Crown, D. A., Mest, S. C., Raymond, C. A. and Russell, C. T., 2016, Stratigraphy of (1) Ceres from geologic and topographic mapping and crater counts using images of the DAWN FC2 camera, 47th Lunar and Planetary Science Conference.

Walsh, K.J., Morbidelli, A., Raymond, S. N., O’Brien, D. P. and Mandell, A. M., 2011, A low mass for Mars from Jupiter's early gas-driven migration, Nature 475, pp. 206-209.

Zambon, F., De Sanctis, M. C., Schröder, S., Tosi, F., Longobardo, A., Ammannito, E., Blewett, D. A., Mittlefehldt, D. W., Li, Jian-Yang, Palomba, E., Capaccioni, F., Frigeri, A., Capria, M. T., Fonte, S., Nathues, A., Pieters, C. M., Russell, C. T. and Raymond, C. A., 2014. Spectral analysis of the bright materials on the asteroid Vesta. Icarus 240, pp. 73-85. 
Tabel 1. List of bright spots detected on Ceres surface, with related geologic, geometric and spectral information. "BS" indicates the number associated to each bright spot. "Feature name" is the name associated to bright units or the quadrangles belonging to when they are unnamed features. "LatMin", "LatMax", "LngMin" and "LngMax" identifies the coordinates including the unit. "Type" is the geomorphological family (E for ejecta, CR for Crater Rims, CW for Crater Walls, CF for Crater Floors, CC for Crater Chain, CP for Crater Peak and NF for bright unit with any geologic features). "Cam" indicates if the feature is also acquired by the FC. "AlbIR", "4.0BC", "4.0BD", "2.7BC", "2.7BD", "3.05BC", "3.05BD", "3.4BC", "3.4BD" are the averaged values of respectively albedo at $1.2 \mu \mathrm{m}$ with a phase angle of $30^{\circ}, 4.0$ band center, 4.0 band deth, 2.7 band center, 2.7 band depth, 3.05 band center, 3.05 band depth, 3.4 band center and 3.4 band depth. "SD" indicates the corresponding standard deviation of spectral parameters.

\begin{tabular}{|c|c|c|c|c|c|c|c|c|c|c|c|c|c|c|c|c|c|c|c|c|c|c|c|c|c|}
\hline BS & Feature name & atMin & atMax & LngMin & LngMax & Type & Cam & AlbIR & SD & $4.0 \mathrm{BC}$ & SD & 4.0BD & SD & $2.7 \mathrm{BC}$ & SD & $2.7 \mathrm{BD}$ & SD & $3.05 \mathrm{BC}$ & SD & 3.05BD & SD & $3.4 \mathrm{BC}$ & SD & 3.4BD & SD \\
\hline B1 & Quad. Ezinu & 60 & 62 & 219 & 221 & E & $\mathrm{N}$ & 0.052 & 0.010 & 3.953; & 0.072 & 0.082 & 0.028 & 2.723; & 0.038 & 0.232 & 0.025 & 3.064; & 0.028 & 0.063 & 0.012 & 3.433; & 0.075 & 0.066 & $0.022 ;$ \\
\hline B2 & Quad. Dantu & 60 & 62 & 134 & 136 & $C R$ & $\mathrm{~N}$ & 0.058 & 0.014 & 3.944 & 0.065 & .072 & 0.0 & 2.723; & 0.006 & 0.256 & $0.019 ;$ & 3.064; & 0.017 & 0.061 & 0.013 & 3.423; & 0.064 & 0.056; & $0.012 ;$ \\
\hline B3 & Quad. Ezinu & 60 & 62 & 220 & 222 & CR & $\mathrm{N}$ & 0.048 & 0.003; & 3.991; & .016 & & 034; & 2.723; & 0.025 & 0.177 & 0.036; & 3.064 & 0.016 & 0.074 & 0.021 & 3.490 & 0.037 & 0.075 & 0.017; \\
\hline B4 & Quad. Coniraya & 56 & 58 & 55 & 57 & $C R$ & Y & 0.053; & 0.010; & 3.953 & 016 & 0.46 & 23; & 2.723; & 0.059 & 0.242 & 0.029 & 3.064; & 0.032 & 0.054 & 0.011 & 3.442 & 0.086; & 0.059; & 0.010 ; \\
\hline B5 & Quad. Coniraya & 54,5 & 55,5 & 58 & 59 & $\mathrm{CW}$ & Y & 0.049; & 0.003; & 3.963 & & 57; & 0.012 & 2.733; & 0.028 & 0.245 & 0.015 & 3.073; & $0.009 ;$ & 0.066 & 0.012 & 3.442; & 0.064; & 0.057; & 0.018; \\
\hline B6 & Omonga & 52 & 55 & 70 & 8 & $C R$ & $\mathrm{~N}$ & 0.054 & 0.014 & 20 & $0.069 ;$ & 4; & 0.020 & 2.723; & 0.005 & 0.233; & 0.012 & 3.064; & 0.017 & 0.056 & 0.014 & 3.357; & 0.078 & 0.061; & 0.014 \\
\hline B7 & Quad.Ezinu & 52 & 54 & 194 & 15 & CR & $\mathrm{N}$ & 0.052; & 0.008 & & $0.101 ;$ & 0.071 & 0.021 & 2.733; & 0.023; & 0.255 & 0.020; & 3.064 & 0.014 & 0.063 & 0.014 & 3.386; & 0.096; & 0.060 & 0.017 ; \\
\hline B8 & Ernutet & 51 & 54 & 43 & 45 & CF & Y & 0.051; & 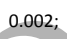 & 3.963 & .023 & 0.074 & 0.015 & 2.733; & 0.019 & 0.220 & 0.024 & 3.073 & 0.007 & 0.075 & 0.010 & 3.423; & 0.031 & $0.102 ;$ & 0.047 ; \\
\hline B9 & Quad. Dantu & 51 & 53 & 13 & 13 & CR & $\mathrm{N}$ & & $0.005 ;$ & 3.944 & 0.046 & 0.063; & 0.014 & 2.723; & 0.010; & 0.258 & 0.021 & 3.073 & 0.015 & 0.060 & 0.016 & 3.423; & 0.078 & 0.065; & 0.017; \\
\hline 10 & Quad. Fejokoo & 52 & 53 & 354 & & $\mathrm{CW}$ & & & 0.001 & 3.982; & 0.010 & 0.101 & 0.037; & 2.733; & 0.007 & 0.223; & 0.021 & 3.073 & 0.004 & 0.066 & 0.007 & 3.461; & 0.047 & 0.081; & 0.028 ; \\
\hline & aad. Co & 47 & 52 & & & & & & & 3.944 & 0.044; & 0.064 & 0.011 & 2.723; & 0.005 & 0.251 & 0.014 & 3.064 & 0.014 & 0.064 & 0.008 & 3.423; & 0.049 & 0.066 & 0.010; \\
\hline 12 & Oxo & 42 & 43 & 359 & & & & & & .995 & 0.006 & 0.138 & 0.012 & 2.733; & 0.017; & 0.177 & 0.013; & 3.064; & 0.008 & o.057; & 0.007 & 3.490; & 0.018 & .097; & .01; \\
\hline 313 & Ezinu & & & & & & & & 0.001 & 981 & 0.01 & 0.081 & 0.006 & 2.723; & 0.005 & 0.236; & 0.012 & 3.07; & 0.004; & 0.067 & 0.004 & 3.423; & 0.035 & 0.054; & 0.006 ; \\
\hline 14 & Quac & & & & & & & & $1 ;$ & 3.944; & 0.025 & 0.069 & 0.009; & 2.723; & 0.030; & 0.238 & 0.003; & .073; & 0.003; & 0.066 & 0.004 & 3.433; & 0.026 & .033; & 11; \\
\hline 15 & Quad. R & & & & & & Y & & 0.009; & 3.963; & 0.028 & 0.051; & 0.011 & 2.723; & 0.005 & 0.254; & 0.010; & 3.073; & 0.007; & 0.065 & 0.010 & 3.442 & 0.078 & 0.043; & 0.016 ; \\
\hline 16 & Quad. & 21 & 22 & (1, & & & $\mathrm{N}$ & 0.046 & 0.001; & 3.953; & 0.011 & 0.070 & 0.011; & 2.733; & 0.015 & 0.257 & 0.008 & 3.073 & 0.005; & 0.075 & 0.009 & 3.433; & 0.049 & .049; & 0.009; \\
\hline 17 & erea & 19 & 21 & & & & Y & 0.0 & 0.016 & 3.999; & 6 ; & 4; & 0 & 760; & 008; & 0 & 1 & 3.077 & 0.012 & 6 & .006; & 3.494; & 1 & .140; & 0.029; \\
\hline 18 & inalia & 19 & 21 & & & & Y & 0.063; & 0.006 & 8 & 0 & 157; & 0. & 754; & 007; & 0.234; & .006; & 79; & 0.004; & 2 & .003; & 3.494; & 0.009; & $9 ;$ & 1; \\
\hline 319 & Dantu1 & 10 & 21 & & & & Y & 9; & 1; & 3; & 4; & 6 ; & 9; & $1 ;$ & 22 & 8; & 07; & 3; & 002; & 7 & 04 & 3.409; & 0.032 & .046; & .006; \\
\hline 20 & Quad. Haulani & 19 &, 5 & 15 & 16 & $\mathrm{EW}$ & Y & 0.046; & $0.001 ;$ & 3.963; & 0.028 & $.070 ;$ & 0.019; & 2.733; & 005; & 0.240 ; & 0.019; & 3.073; & 0.006; & 0.074 & 0.013; & 3.490; & 0.077 & 0.066 & 0.026 ; \\
\hline
\end{tabular}




\begin{tabular}{|c|c|c|c|c|c|c|c|c|c|c|c|c|c|c|c|c|c|c|c|c|c|c|c|c|c|}
\hline B21 & Dantu2 & 16 & 18 & 134 & 136 & $C R$ & $N$ & 0.053 & 0.005 & 3.953; & 0.012 & 0.058 & 0.007 & 2.723 & 0.000 & $0.251 ;$ & 0.006 & 3.6 & & б.086; & 0.006 & 3.442 & 0.049 & 0.071 & 0.010; \\
\hline B22 & Dantu3 & 15 & 17 & 141 & 143 & E & $Y$ & 0.039 & 0.001; & 3.970; & 0.009 & 0.113 & 0.012 & 2.724 & 0.004 & 0.233 & 0.004 & 3.073; & 0.001; & 0.072 & 0.006 & 3.445 & 0.032 & 0.054 & 0.006 \\
\hline B23 & Quad. Haulani & 14 & 16 & 9 & 11 & $\mathrm{LF}$ & $N$ & 0.034 & 0.000 & 3.944 & 0.016 & 0.070 & 0.011 & 2.723; & 0.044 & 0.239 & 0.0 & 3.073; & ס.005; & 0.064 & 0.007 & 3.442 & 0.049 & 0.038 & 0.010 \\
\hline B24 & Quad. Haulani & 7 & 8 & 14,5 & 15 & $C R$ & $Y$ & 0.046 & 0.002 & 3.953; & 0.013 & 0.065 & 0.014 & 2.733; & 0.002 & 0.23 & 0.009 & 3.08 & 0.007 & 0.065 & 0.011; & 3.442 & 0.058 & 0.041 & 0.016 \\
\hline B25 & Quad. Rongo & 5 & 7 & 321 & 323 & $\mathrm{CW}$ & $\mathrm{N}$ & 0.046 & 0.001; & 3.944; & 0.023 & 0.058 & 0.008 & 2.733; & 0.005 & 0.252 & 0.008 & 3.073; & 0.003 & 0.073 & 0.006 & 3.405 & 0.064 & 0.040 & 0.010; \\
\hline B26 & Rao & 6 & 7 & 121 & 122 & $C R$ & $Y$ & 0.048 & 0.001; & 3.944 & 0.018 & 0.057 & 0.007 & 2.723; & 0.005; & 0.257 & 0.014 & 3.073; & 0.005 & 0.085 & 0.009 & 3.423 & 0.070 & 0.051; & 0.009; \\
\hline B27 & Haulani & 3 & 5 & 10 & 11 & E & $Y$ & 0.052 & 0.004 & 3.982 & 0.022 & 0.084 & 0.027 & 2.733 & 0.016 & 0.202 & 0.033 & 3.073; & 0.016 & 0.055 & 0.017; & 3.461 & 0.055 & 0.060 & 0.019; \\
\hline B28 & Quad. Haulani & 3 & 5 & 68 & 70 & $C R$ & $Y$ & 0.034 & 0.001; & 3.953; & 0.035 & 0.065 & 0.015 & 2.723 & 0.005, & 0.247 & 0.007 & 3.073; & 0.009 & 0.067 & 0.005 & 3.423 & 0.055 & 0.040; & 0.010 \\
\hline B29 & Quad. Kerwan & 2 & 3 & 137 & 138 & $\mathrm{cW}$ & $Y$ & 0.052 & 0.004 & 3.953; & 0.022 & 0.063 & 0.019 & 2.733 & 0.006 & 0.248 & 0.010 & 3.073; & 0.005 & 0.082 & 0.008 & 3.423 & 0.070 & 0.046 & 0.016 \\
\hline взо & Quad. Rongo & -2 & 0 & 309 & 311 & E & $Y$ & 0.045 & 0.001; & 3.973; & 0.007 & 0.094 & $0.007 ;$ & 2.723 & 0.001; & 0.246 & 0.003 & 3.073; & 0.002 & 0.083 & 0.003; & 3.441 & 0.019 & 0.063 & 0.004; \\
\hline B31 & Quad. Kerwan & -3 & -2 & 135 & 136 & $C R$ & $\mathrm{~N}$ & 0.050 & 0.002 & 3.963; & 0.015 & 0.069 & 0.016 & 2.733 & 0.024 & 0.249 & 0.011 & 3.073; & 0.006 & 0.084 & 0.008 & 3.423 & 0.060 & 0.051 & 0.011; \\
\hline B32 & Quad. Rongo & -4 & -3 & 299 & 299,5 & $C R$ & $\mathrm{~N}$ & 0.049 & 0.002 & 3.953; & 0.013 & 0.078 & 0.011 & 2.733 & 0.005 & 0.238 & 0.011 & 3.073; & 0.007 & 0.072 & 0.007 & 3.442 & 0.048 & 0.043; & 0.012 \\
\hline Bз3 & Quad. Rongo & -6 & -4 & 302 & 304 & $\mathrm{cW}$ & $\mathrm{N}$ & 0.048 & 0.002 & 3.963 & 0.020 & 0.063 & 0.011 & 2.733; & 0.007 & 0.251 & 0.013 & 3.073; & 0.007 & 0.075 & 0.010 & 3.442 & 0.069 & 0.058 & 0.014 \\
\hline B34 & Lociyo & -8 & -6 & 230 & 231 & $\mathrm{CF}$ & $Y$ & 0.045 & 0.001; & 3.953; & 0.020 & & 3 & 2.733; & 0.017 & 0.241 & 0.015 & 3.073; & 0.008 & 0.062 & 0.008 & 3.442 & 0.071 & 0.035 & 0.015 \\
\hline B35 & Quad. Rongo & -9 & -8 & 312 & 313 & $\mathrm{CW}$ & Y & 0.048 & 0.002 & 3.953 & 0.016; & $0.057 ;$ & 0.010 & 2.733; & 0.026 & 0.244 & 0.015 & 3.073; & 0.007 & 0.070 & 0.010; & 3.442 & 0.077 & 0.054 & 0.014 \\
\hline B36 & Quad. Rongo & -9 & -8 & 353 & 353,5 & $\mathrm{CR}$ & $\mathrm{N}$ & 0.048 & 0.002 & 3.963; & 28; & 0.070 & 0.019; & 2.733; & 0.022 & 0.252 & 0.011 & 3.073; & 0.007 & 0.066 & 0.009; & 3.442 & 0.079 & 0.037; & 0.012 \\
\hline B37 & Quad. Rongo & -12 & -10 & 311 & 312 & $\mathrm{CF}$ & $\mathrm{N}$ & 0.039 & 0.001; & 3.972; & 7 & 0.094 & 0.013 & 2.733; & 0.005 & 0.211 & 0.014 & 3.073; & 0.005 & 0.060 & 0.011; & 3.461 & 0.040 & 0.061 & 0.012 \\
\hline B38 & Quad. Nawish & -17 & -15 & 186 & 187,3 & $C R$ & $Y$ & 0.048 & 0.002 & 3.944 & 9; & 0.061 & 0.016 & 2.733 & 0.006 & 0.232 & 0.010 & 3.073; & 0.007 & 0.066 & 0.008 & 3.433 & 0.078 & 0.046 & 0.017 \\
\hline B39 & Quad. Occator & -17 & -16 & 255,2 & 255,5 & $C R$ & $Y$ & 0.044 & 0.000 ; & 3.953; & 0,021 & 0.065 & 0.007 & 2.733; & 0.005 & 0.243 & 0.009 & 3.073; & 0.003 & 0.072 & 0.006 & 3.442 & 0.076 & 0.043; & 0.017; \\
\hline B40 & Quad. Rongo & -19 & -18 & 306 & 307 & $\mathrm{CR}$ & $\mathrm{N}$ & 0.046 & 0.001 & 3.944; & 0.031 & 0.060 & 0.012 & 2.733; & 0.019 & 0.246 & 0.011 & 3.073; & 0.005 & 0.074 & 0.010; & 3.414 & 0.066 & 0.048 & 0.013; \\
\hline B41 & Quad. Kerwan & -21 & -20 & 84 & 86 & $\mathrm{CR}$ & Y & 0.045 & 0.001; & 3.963; & 0.000 & 0.066 & 0.022 & 2.723 & 0.000 & 0.248 & 0.003 & 3.073; & 0.000 & 0.076 & 0.026 & 3.423 & 0.093 & 0.058 & 0.009 \\
\hline B42 & Quad. Haulani & -23 & -20 & 22 & 26 & $C R$ & & & & 3.953; & 0.059 & 0.062 & 0.017 & 2.733; & 0.004 & 0.256 & 0.011 & 3.073; & 0.021 & 0.061 & 0.012 & 3.405 & 0.089 & 0.064 & 0.029; \\
\hline B43 & Quad. Rongo & -21 & -20 & 290 & 291 & LF & & & & 3.963 & 0.048 & 0.076 & 0.016 & 2.733; & 0.028 & $0.239 ;$ & 0.014 & 3.073; & 0.004 & 0.073 & 0.007 & 3.423 & 0.061 & 0.039 & 0.011; \\
\hline B44 & Quad. Urvara & -23 & -22 & 180 & 182 & & N & & 0.004 & 3.953; & 0.050 & 0.071 & 0.017 & 2.733; & 0.030 & 0.247 & 0.012 & 3.073; & 0.011 & 0.075 & 0.010; & 3.433 & 0.042 & 0.053; & 0.027; \\
\hline B45 & Quad. Yalode & -21 & -20 & 280 & 281 & & N & 0.049 & 0.006 & 3.953 & 0.038 & 0.061 & 0.015 & 2.733; & 0.005 & 0.251 & 0.020 & 3.073; & 0.011 & 0.073 & 0.016 & 3.433 & 0.076 & 0.065 & 0.018 \\
\hline B46 & Quad. Urvara & -24 & -23 & 250 & 251 & & $\mathrm{~N}$ & 0.044 & 0.001 & 3.960 & 0.011 & 0.075 & 0.010; & 2.733; & 0.005 & 0.247 & 0.007 & 3.073; & 0.004 & 0.072 & 0.006 & 3.430 & 0.036 & 0.05 & 0.009; \\
\hline B47 & Quad. Toharu & -28 & -25 & 140 & 14 & CR & $\mathrm{Y}^{\prime}$ & 0.036 & 0.001 & 3.963; & 0.015 & 0.063 & 0.012 & 2.733; & 0.016 & 0.255 & 0.010 & 3.073; & 0.005 & 0.084 & 0.008 & 3.433 & 0.059; & 0.051; & 0.010; \\
\hline B48 & Quad. Yalode & -28 & -25 & 342 & & $\mathrm{CK}$ & $\mathrm{N}$ & 0.048 & 0.003; & 3.963; & 0.016 & 0.079 & 0.025 & 2.733; & 0.000 & 0.271 & 0.015 & 3.073; & 0.011 & 0.061 & 0.010; & 3.386 & 0.073 & 0.056 & 0.009; \\
\hline B49 & Quad. Urvara & -26 & -25 & 187 & & & $Y$ & 0.045 & 0.001; & 3.963; & 0.034 & 0.066 & 0.015 & 2.733; & 0.026 & 0.243 & 0.013 & 3.073; & 0.006 & 0.066 & 0.009; & 3.433 & 0.058 & 0.046 & 0.014 \\
\hline B50 & Quad. Yalode & -28 & -26 & & $\$ 10,4$ & Lr & $Y$ & 0.047 & 0.000 & 3.944 & 0.020 & 0.069 & 0.006 & 2.723 & 0.005 & 0.238 & 0.010 & 3.073; & 0.004 & 0.073; & 0.008 & 3.442 & 0.031; & 0.046 & 0.016 \\
\hline B51 & Quad. Yalode & -28 & -26 & 342 & 3 & CW & $\mathrm{N}$ & 0.047 & 0.002 & 3.953 & 0.010 & 0.054 & 0.013 & 2.733; & 0.005 & 0.247 & 0.017 & 3.073; & 0.006 & 0.075 & 0.012 & 3.433; & 0.046 & 0.048 & 0.010 \\
\hline B52 & Quad. Toharu & -30 & 2 & 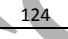 & 126 & E & $\mathrm{N}$ & 0.052 & $0.004 ;$ & 3.963; & 0.013 & 0.064 & $0.015 ;$ & 2.733 & 0.030 & 0.255 & 0.013 & 3.073; & 0.006 & 0.078 & 0.013; & 3.433 & 0.071 & 0.060 & 0.010; \\
\hline
\end{tabular}




\begin{tabular}{|c|c|c|c|c|c|c|c|c|c|c|c|c|c|c|c|c|c|c|c|c|c|c|c|c|c|}
\hline B53 & Quad. Toharu & -30 & -28 & 128 & 131 & $C R$ & $\mathrm{~N}$ & 0.052 & 0.005 & 3.963 & 0.013 & 0.067 & 0.015 & 2.733 & 0.032 & 0.257 & 0.014 & 3.073 & 0.007 & 0.077 & 0.014 & 3.442 & 0.065 & 0.059 & 0.011 \\
\hline B54 & Quad. Toharu & -32 & -29 & 100 & 103 & $C R$ & N & 0.049 & 0.003 & 3.953; & 0.105 & 0.064 & 0.018 & 2.733 & 0.009 & 0.260 & 0.014 & 3.015 & $0.011 ;$ & 0.080 & 0.010 & 3.423 & 0.055 & 0.056 & 0.020 \\
\hline B55 & Yalode1 & -31 & -30 & 302 & 303 & $\mathrm{cW}$ & Y & 0.051; & 0.003 & 3.953; & 0.012 & 0.072 & 0.012 & 2.733 & 0.003 & 0.243; & n & 3.073; & 0.005 & 0.080 & 0.010 & 3.423 & 0.048 & 0.055 & 0.011 \\
\hline B56 & Quad. Sintana & -32 & -31 & 9 & 11 & E & $\mathrm{N}$ & 0.054 & 0.007 & 3.944 & 0.068 & 0.080 & 0.045 & 2.657 & 0.053 & 0.264 & 0.023 & 3.073 & 0.020 & 0.057 & 0.014 & 3.442 & 0.097; & 0.058 & 0.018 \\
\hline B57 & Yalode2 & -32 & -31 & 298 & 299 & $\mathrm{CW}$ & $\mathrm{Y}$ & 0.045 & 0.001 & 3.963; & 0.028 & 0.066 & 0.022 & 2.733 & 0.023 & 0.228 & 0.013 & 3.073 & 0.016 & 0.059 & 0.011 & 3.442 & 0.057 & 0.039 & 0.015 \\
\hline B58 & Yalode3 & -32 & -31 & 305,8 & 306 & $C R$ & Y & 0.052 & 0.003 & 3.963; & 0.016 & 0.070 & 0.015 & 2.733; & 0.004 & 0.236 ; & 0.011 & 3.073; & 0.006 & 0.078 & 0.008 & 3.423 & 0.063; & 0.052 & 0.010 \\
\hline B59 & Yalode4 & -35 & -33 & 301,5 & 302 & $\mathrm{cW}$ & $\mathrm{N}$ & 0.049; & 0.003 & 3.963 & 0.031 & 0.064 & 0.012 & 2.733 & 0.00 & $0.229 ;$ & 0.015 & 3.073 & 0.006 & 0.070 & 0.010 & 3.452 & 0.066 & 0.044 & 0.017 \\
\hline B60 & Quad. Yalode & $-35,5$ & -33 & 305 & 307 & LF & $N$ & 0.049; & 0.003 & 3.963; & 0.035 & 0.068 & 0.015 & 2.733; & 0.016 & 0.248 & 0.013 & 3.073; & 0.007 & 0.083 & 0.009 & 3.433; & 0.055 & 0.059 & 0.015 \\
\hline B61 & Quad. Toharu & -36 & -34 & 164 & 166 & $\mathrm{E}$ & $\mathrm{N}$ & 0.052 & 0.005 & 3.972 & 0.020 & 0.078 & 0.024 & 2.733; & .027; & 0.239 & 0.028 & 3.073; & 0.008 & 0.078 & 0.013 & 3.471; & 0.078 & 0.062 & 0.018 \\
\hline B62 & Urvara1 & -37 & -35 & 241 & 242 & $\mathrm{CW}$ & $\mathrm{N}$ & 0.045 & 0.001 & 3.953 & 0.015 & 0.068 & 0.012; & $33 ;$ & 0.005 & 0.252 & 0.009; & 3.073 & 0.005 & 0.075 & 0.008 & 3.442 & 0.055 & 0.046 & 0.013 \\
\hline B63 & Quad. Sintana & $-36,5$ & $-35,5$ & 81,5 & 82 & $\mathrm{cW}$ & $N$ & 0.049; & 0.003 & 3.953; & 0.057 & 0.056 & 0.015 ; & 33; & 0.010 ; & 0.265 & 0.019; & 3.073 & 0.008 & 0.077 & 0.011 & 3.442 & 0.096 & 0.053 & 0.019 \\
\hline B64 & Quad. Yalode & -37 & $-35,5$ & 306,5 & 307 & LF & $\mathrm{N}$ & 0.047 & 0.001 & 3.953; & 0.015 & 0.073 & 0.011 & 2.733 & 0.016 & 0.247 & 0.015 & 3.073 & 0.007 & 0.085 & 0.012 & 3.423 & 0.071 & 0.055 & 0.012 \\
\hline B65 & Quad. Sintana & -37 & -36 & 81 & 82 & $\mathrm{cW}$ & $\mathrm{N}$ & 0.038 & 0.001 & 3.972 & 0.001 & 0.065 & 0. & 2.723 & 0.001 & 0.249 & 0.001 & 3.064 & 0.001 & 0.067 & 0.001 & 3.452 & 0.001 & 0.055 & 0.001 \\
\hline B66 & Urvara2 & -37 & -36 & 246 & 248 & $\mathrm{CW}$ & Y & 0.047 & 0.004 & 3.953; & 0.061 & & 0.020 & 2.733; & 0.020 & 0.253 & 0.017 & 3.073; & 0.011 & 0.071 & 0.012 & 3.442 & 0.074 & 0.054 & 0.021; \\
\hline B67 & Darzamat & -42 & -38 & 78 & 80 & $\mathrm{cW}$ & $\mathrm{N}$ & 0.048 & 0.002 & 3.963 & 0.036 & ; & 0.014 & 2.733 & 0.029 & 0.265 & 0.015 & 3.073; & 0.007 & 0.089 & 0.012 & 3.423 & 0.082 & 0.054 & 0.017 \\
\hline B68 & Kupalo & -42 & -40 & 170 & 172 & $\mathrm{cW}$ & N & 0.047 & 0.005 & 3.991; & $4 ;$ & 0.107 & 0.021 & 2.733 & 0.005 & 0.216 & 0.020 & 3.064 & 0.012 & 0.068 & 0.009 & 3.490 & 0.050 & 0.084 & 0.017 \\
\hline B69 & Urvara 3 & -42 & -40 & 255,5 & 256,5 & $\mathrm{CF}$ & N & 0.045; & 0.001 & 3.963; & $;$ & 0.067 & 0.019 & 2.733 & 0.037 & 0.241 & 0.015 & 3.073; & 0.013 & 0.070 & 0.011 & 3.433 & 0.051 & 0.049 & 0.012 \\
\hline B70 & Quad. Sintana & -41 & -40 & 5,5 & 6,5 & $\mathrm{cW}$ & $\mathrm{N}$ & 0.051; & 0.004 & 3.953 & 0.017 & 0.057 & 0.011; & 2.733 & 0.015 & 0.256 & 0.019; & 3.073 & 0.008 & 0.068 & 0.015 & 3.442 & 0.076 & 0.045 & 0.017 \\
\hline B71 & Yalode5 & -41 & -40 & 276 & 277 & $\mathrm{cW}$ & Y & 0.046 & 0.001 & 3.953; & 0,014 & 0.071 & 0.010 & 2.733; & 0.004 & 0.241 & 0.014 & 3.073 & 0.008 & 0.070 & 0.011 & 3.442 & 0.057 & 0.050 & 0.013 \\
\hline B72 & Yalode6 & $-42,5$ & $-41,5$ & 296,3 & 296,5 & $\mathrm{CW}$ & $N$ & 45; & 0.003 & 3.953; & 0.016 & 0.062 & 0.007 & 2.733 & 0.005 & 0.240 & 0.014 & 3.073 & 0.010 & 0.067 & 0.013 & 3.423 & 0.045 & 0.054 & 0.009 \\
\hline B73 & Yalode7 & -44 & -43 & 296,8 & 297,2 & $\mathrm{cW}$ & N & $5 ;$ & 0.002 & 3.953; & 0.023 & 0.054 & 0.013 & 2.733 & 0.031; & 0.242 & 0.012 & 3.073 & 0.006 & 0.073 & 0.010 & 3.414 & 0.060 & 0.052 & 0.014 \\
\hline B74 & Darzamat & -45 & -43 & 76 & 77 & CW & & & 2; & 3.963; & 0.023 & 0.058 & 0.01; & 2.733 & 0.013 & 0.259 & 0.012 & 3.073; & 0.004 & 0.083 & 0.007 & 3.442 & 0.051 & 0.04 & 0.011 \\
\hline B75 & Urvara 4 & -48 & -47 & 251,5 & 252 & $\mathrm{CF}$ & & & 0.001; & 3.953; & 0.020 & 0.075 & 0.012 & 2.733 & 0.017 & 0.239 & 0.016 & 3.073 & 0.009 & 0.071 & 0.012 & 3.423 & 0.057 & 0.062 & 0.016 \\
\hline B76 & Yalode8 & -49 & -48 & 298 & 298,5 & & $\mathrm{~N}$ & 047; & 0.001; & 3.953 & 0.010 & 0.072 & 0.010 & 2.733; & 0.005 & 0.236 & 0.017 & 3.073 & 0.009 & 0.075 & 0.009 & 3.433 & 0.058 & 0.052 & 0.016 \\
\hline B77 & Yalode9 & -51 & -50 & 293,6 & 293,8 & & $\mathrm{~N}$ & 0.049 & 0.002 & 3.953; & 0.040 & 0.080 & 0.014 & 2.733 & 0.028 & 0.233 & 0.012 & 3.073 & 0.007 & 0.070 & 0.011 & 3.442 & 0.028 & 0.053 & 0.012 \\
\hline B78 & Quad. Toharu & -52 & -51 & 170 & 171 & & $\mathrm{~N}$ & ; & 0.006 & 3.953 & 0.041 & 0.058 & 0.014 & 2.733 & 0.028 & 0.259 & 0.015 & 3.073 & 0.008 & 0.086 & 0.012 & 3.423 & 0.081 & 0.048 & 0.019 \\
\hline B79 & Quad. Urvara & -52 & -51 & 191 & & & $\mathrm{~N}^{\prime}$ & 0.047 & 0.002 & 3.953; & 0.022 & 0.064 & 0.020 & 2.733; & 0.014 & 0.253 & 0.019; & 3.073 & 0.017 & 0.074 & 0.009 & 3.442 & 0.090 & 0.045 & 0.028 \\
\hline B80 & Quad. Urvara & -52 & -51 & 232 & & & $\mathrm{~N}$ & 0.047; & 0.001 & 3.953 & 0.017 & 0.058 & 0.010 & 2.733 & 0.046 & 0.248 & 0.014 & 3.073 & 0.012 & 0.079 & 0.010 & 3.433 & 0.067 & 0.046 & 0.012 \\
\hline B81 & Urvara3 & -54 & -52 & 247 & & & $\mathrm{~N}$ & 0.046 & 0.001 & 3.944 & 0.016 & 0.062 & 0.010 & 2.733; & 0.007 & 0.236 & 0.017 & 3.073 & 0.006 & 0.073 & 0.011 & 3.433 & 0.061 & 0.043 & 0.015 \\
\hline B82 & Quad. Urvara & -54 & -53 & & & cw & $\mathrm{N}$ & 0.052 & 0.004 & 3.963; & 0.051 & 0.071 & 0.034 & 2.723 & 0.044 & 0.245 & 0.023 & 3.073 & 0.023 & 0.063 & 0.015 & 3.452 & 0.063 & 0.063 & 0.018 \\
\hline B83 & Chaminuka1 & -55 & -54 & & 124 & $\mathrm{cW}$ & $N$ & 0.044 & 0.036 & 3.953; & 0.072 & 0.063 & 0.022 & 2.723 & 0.027 & 0.263 & 0.026 & 3.073; & 0.013; & 0.082 & 0.012 & 3.423 & 0.075 & 0.055 & 0.014 \\
\hline B84 & Quad. Toharu & -56 & & & 111 & $\mathrm{CR}$ & $\mathrm{N}$ & 0.032; & 0.005 & 3.953; & 0.105 & 0.057 & 0.013 & 2.733 & 0.005 & 0.267 & 0.015 & 3.073; & 0.005 & 0.074 & 0.010 & 3.442 & 0.082 & 0.041 & 0.021 \\
\hline
\end{tabular}


